\title{
DINÂMICA INTRARREGIONAL DO BRASIL: QUEM DIRIGE O CRESCIMENTO INDUSTRIAL DAS REGIÕES BRASILEIRAS?
}

\author{
Elano Ferreira Arruda * \\ Roberto Tatiwa Ferreira ${ }^{\dagger}$
}

\begin{abstract}
Resumo
Analisa-se a dinâmica intrarregional da indústria brasileira identificando os estados que conduzem o crescimento de suas regiões e as repercussões de choques no crescimento das exportações sobre a atividade industrial. Utilizam-se informações sobre produção industrial, inflação, exportações e taxa de câmbio e modelos vetoriais dinâmicos restritos. O estado da Bahia apresentou as maiores repercussões na atividade industrial sobre os demais estados do Nordeste. No Sudeste, destaque para São Paulo. A região Sul apresentou a maior integração intrarregional. Considerando os choques no crescimento das exportações, apenas Bahia, São Paulo, Rio de Janeiro, Rio Grande do Sul e Paraná responderam positivamente.
\end{abstract}

Palavras-chave: Economia Regional, Dinâmica Industrial, Exportações Estaduais.

\begin{abstract}
This paper analyzes the Brazilian intraregional industry dynamics in order to identify which states lead the industrial growth and to quantify the effects of export shocks in growth and its transmission processes on the state's industrial activity. To this end, an autoregressive vector with parameter constraints was used. The results show that Bahia state has the highest and most permanent effects on the other Northeastern states, while in the Southeast region this is assigned by the state of São Paulo. Furthermore, the Southern region had the greatest regional integration and export shocks had positive effects only in the states of Bahia, São Paulo, Rio de Janeiro, Rio Grande do Sul and Paraná.
\end{abstract}

Keywords: Regional Economics, Industrial Dynamics, State Export.

JEL classification: R10, R15.

DOI: http://dx.doi .org/10.1590/1413-8050/ea404

\footnotetext{
* Universidade Federal do Ceará. E-mail: elano@ufc.br

† Universidade Federal do Ceará. E-mail: rtf2@uol.com.br
} 


\section{Introdução}

Um tópico bastante controverso da teoria econômica é a análise e o tratamento das disparidades regionais de um país. As diferenças de renda per capita, produção, oportunidades, capital humano, produtividade inter/intrarregionais denotam o grau de desequilíbrio regional. Mudanças econômicas oriundas de choques nos preços de insumos, no clima, no padrão tecnológico, nas políticas públicas, entre outras, podem ocorrer em uma dada região específica e afetar apenas esta região, ou atingir todas as regiões do país de forma simultânea, ou ainda, ocorrer em uma dada região e gradualmente serem repassadas para uma ou mais regiões.

A possibilidade de transmissão dos efeitos supracitados pode ser explicada de diferentes formas, seja pela existência de externalidades de localização como em Marshall (1890), Arrow (1962) e Romer (1986), entre outros, ou em virtude dos efeitos antagônicos de retardamento (backwash effect) e de espraiamento (spread effect) propostos por Myrdal (1963) que gerariam um crescimento regional divergente, ou ainda pelos efeitos oriundos dos fluxos comerciais e dos fatores de localização industrial argumentados pela Nova Geografia Econômica presentes em Krugman (1991), Krugman \& Venables (1990, 1995) e Baldwin et al. (2003).

Portanto, uma importante agenda de pesquisa é quantificar de que forma a dinâmica de um estado específico afeta os demais em sua região, por meio de evidências empíricas que mostrem se a relação de interdependência entre os mesmos é positiva ou negativa, e se há estados que influenciam essa dinâmica mais do que outros. Nesse sentido, Tatiwa \& Arruda (2011) conduzem um exercício empírico e mostram que há uma grande interdependência em termos de atividade industrial entre as regiões brasileiras e destas com o setor externo, confirmando a importância de se levar consideração o setor externo em estudos que analisam o comportamento dinâmico inter-regional. Além disso, a região Sudeste se destacou por apresentar os maiores e mais persistentes efeitos sobre as demais regiões. Os choques positivos no crescimento industrial da região Sul do Brasil também apresentaram impactos positivos sobre a dinâmica industrial nas demais. Entretanto, nas mesmas condições, o Nordeste influenciou negativamente a taxa de crescimento da produção industrial das demais regiões.

Os autores mostram ainda que a contribuição do setor externo para a atividade econômica regional depende fundamentalmente da natureza do setor exportador de cada região, uma vez que apenas o Sudeste reagiu positivamente, enquanto que Nordeste e Sul apresentaram uma queda na dinâmica industrial em resposta a choques nas exportações. Na linha de Haddad et al. (2002), Perobelli \& Haddad (2006a), tal resultado pode ocorrer devido a uma maior participação das atividades agrícolas nas exportações das regiões Sul e Nordeste em detrimento da forte indústria exportadora de manufaturados presente no Sudeste brasileiro. Além disso, confirmam o resultado de Porto (2002), que mostra que a abertura comercial brasileira tem contribuído para o agravamento das disparidades regionais.

Diante das evidências supracitadas, surgem as seguintes questões: que estados se mostram mais importantes para a dinâmica industrial das regiões brasileiras ou, em outras palavras, quem dirige o crescimento na indústria de 
cada região do Brasil ${ }^{1}$ Em que regiões essas interações se mostram mais fortes? E quais apresentam resultados positivos do crescimento das exportações sobre o crescimento da indústria em cada região? As exportações apresentam repercussões assimétricas sobre a atividade industrial em uma perspectiva intrarregional?

Portanto, o presente estudo tem como objetivo examinar a dinâmica intrarregional do Brasil com vistas a fornecer evidências empíricas sobre as indagações acima, por meio de um modelo vetorial dinâmico com restrições. Tal técnica se faz apropriada para este objetivo, uma vez que o modelo restrito, como mostra Lutkepohl (2005), provê um estimador robusto e funções de impulso resposta com propriedades estatísticas desejáveis. Para tal, serão utilizadas informações mensais entre janeiro de 1996 e fevereiro de 2010 sobre produção industrial, inflação e exportações em nível estadual, ${ }^{2}$ além da taxa de câmbio, considerada exógena nos modelos utilizados. Este trabalho inova ao utilizar uma técnica ainda não aplicada em estudos desta natureza, ao considerar o setor externo, via exportações, em um modelo com perspectivas regionais e por examinar o caminho de transmissão e as repercussões da atividade industrial e crescimento das exportações em um contexto intrarregional.

Além desta introdução, este trabalho possui mais quatro seções. A próxima consiste em destacar tanto os aspectos teóricos quanto as aplicações empíricas que versam sobre o tema economia regional, indústria e integração regional e comércio e crescimento regional com foco na economia brasileira. A terceira seção se reserva à apresentação e análise da base de dados. A descrição da metodologia econométrica é tema da quarta seção. A análise e discussão dos resultados são feitas em seguida. E, por fim, são tecidas as considerações finais do estudo.

\section{Revisão de Literatura}

O debate em torno dos desequilíbrios regionais iniciou-se com as ideias de crescimento regional divergente de Myrdal (1963) contrapondo-se a expansão convergente de Willianson (1965). O primeiro autor argumentava a existência de dois efeitos antagônicos entre si, chamados de retardamento (backwash ef$f e c t$ ) e espraiamento (spread effect). O primeiro é caracterizado como os estímulos que uma região beneficiada com uma nova indústria, por exemplo, recebe ao gerar migração da mão de obra, efeitos multiplicadores do investimento realizado, crescimento do comércio e provimento de uma melhor infraestrutura em detrimento das demais regiões do país, potencializando as distorções iniciais. Na outra direção, haveria as externalidades positivas do aumento da atividade econômica dos polos de crescimento em direção às regiões menos desenvolvidas por meio do aumento na demanda por insumos realizada pela primeira região sobre as demais, da possibilidade de transferência da tecnologia, de deseconomias externas, do acréscimo nos custos da mão-de-obra na região que recebeu a indústria, dentre outros. Segundo o autor, apesar de an-

\footnotetext{
${ }^{1}$ Uma questão interessante seria quantificar os efeitos entre estados de diferentes regiões. Entretanto, dada a limitação do tamanho da amostra e o número de parâmetros envolvidos na estimação de um único VAR para todos os estados, tal análise torna-se inviável com a metodologia utilizada nesse estudo; a qual, vale ressaltar, atende ao enfoque intrarregional desse estudo. Assim, optou-se pela estimação de um sistema dinâmico para cada região analisada

${ }^{2}$ Devido à indisponibilidade de dados sobre produção industrial de seus estados no período considerado, as regiões Norte e Centro-Oeste foram excluídas da análise.
} 
tagônicas, tais repercussões não garantiriam o equilíbrio, pelo menos no curto prazo, gerando divergência no crescimento regional.

Já para Willianson (1965), os resultados divergentes não se aplicariam a todas as situações e níveis de desenvolvimento das regiões, mas seriam típicas de determinados estágios do processo de desenvolvimento econômico. Detalhando tal visão, Azzoni (1993) afirma que, com o desenvolvimento, deseconomias externas se apresentam na região mais rica e economias de aglomeração começam a aparecer nas regiões mais pobres, acarretando em uma inversão no fluxo de capitais, que agora buscam melhores oportunidades e maior rentabilidade na região mais pobre. Argumenta ainda que um governo suscetível às questões regionais deva agir na direção da promoção da igualdade e convergência.

Portanto, as repercussões entre unidades econômicas foram explicadas inicialmente via efeitos retardamento ou espraiamento. O primeiro reflete um efeito substituição ou concorrência em termos de insumos, provocando uma transmissão negativa da atividade industrial entre as regiões, enquanto que o segundo aponta um efeito complementar, ou seja, ambas as regiões seriam beneficiadas com aumento na interação comercial, ganhos no fornecimento de insumos, inversão no fluxo de capitais, externalidades positivas e efeitos de aglomeração.

A literatura evoluiu na tentativa de elucidar os aspectos que se encontravam obscuros nos estudos anteriores. Nesse sentido, destacaram-se os modelos neoclássicos de crescimento regional e os modelos de expansão regional baseados no lado da demanda com restrições no balaço de pagamentos. $\mathrm{Na}$ primeira classe de estudos, destaca-se o realizado por Smith (1975) que desenvolve um modelo em que os movimentos de capital e trabalho estão explicitamente incluídos. O autor considera os segmentos da produção, do investimento e as condições do mercado de trabalho e testa o modelo para dados dos estados americanos concluindo que os resultados observados estão de acordo com os esperados pelo modelo, ou seja, que o capital move-se na direção das regiões com maior taxa de retorno; que os trabalhadores migram em direção aos estados com maior remuneração; e que há convergência de renda per capita entre as regiões. Logo, os choques na atividade econômica em regiões mais desenvolvidas repercutem positivamente sobre as demais que receberiam um influxo de capital por apresentarem custos reduzidos e maiores taxas de retorno provocando também efeitos positivos sobre as primeiras.

Os elementos constantes nas hipóteses formuladas por Myrdal (1963) foram idealizados em um contexto regional inicialmente por Kaldor (1970), e formalizadas em um modelo teórico por Dixon \& Thirlwall (1975), usualmente denominado como modelo Kaldor-Dixon-Thirlwall (KDT). Um modelo com duas regiões, inicialmente isoladas entre si, cada qual com uma área agrícola e um centro comercial e industrial. Em determinado momento o comércio é aberto entre as duas regiões. Esses modelos funcionam sob retornos crescentes de escala, com círculos virtuosos de efeitos backwash e spread entre a produção e o crescimento da produtividade, hipótese conhecida por relação de Verdoorn. Para esses autores, o crescimento regional é determinado fundamentalmente pelo crescimento da demanda por exportações, ao qual as taxas de crescimento do investimento e do consumo devem se ajustar. Portanto, um modelo que busca explicar as interações regionais deve considerar as repercussões econômicas do crescimento das exportações sobre a atividade econômica. 
Em seguida vieram os modelos de crescimento neoclássicos que incorporam dependência espacial, os modelos da Nova Geografia Econômica e os modelos de Aglomeração e Economias de Escala. O trabalho de Corrado et al. (2005) reconheceu que na existência de heterogeneidade espacial, haveria clubes de regiões que convergem para diferentes taxas de crescimento de longo prazo. A abordagem da Nova Geografia Econômica baseia-se na hipótese de que o espaço é um fator crucial para determinar o desenvolvimento econômico, sobretudo nos aspectos subjacentes aos fluxos comerciais e a localização industrial (Krugman 1991, Krugman \& Venables 1990, 1995, Baldwin et al. 2003). Esses autores apoiam-se nas hipóteses de concorrência monopolística e retornos crescentes de escala, onde as empresas podem produzir mais barato, concentrando a produção em um número menor de "plantas" geograficamente co-localizadas e com diferenciação do produto.

As aglomerações e economias de escala, ou simplesmente MAR Spillovers (Marshall 1890, Arrow 1962, Romer 1986), minimizam os custos de transporte e de transação de bens, pessoas ou ideias e, assim, sugerem que as empresas de um dado setor localizadas perto de outras de sua cadeia de abastecimento podem beneficiar-se de tais transbordamentos.

Portanto, as transmissões da atividade industrial no âmbito intrarregional investigadas nesse estudo podem ser positivas ou negativas dependendo da heterogeneidade espacial (Corrado et al. 2005); ou do grau de interação comercial entre as unidades econômicas em que as indústrias reduzem seus custos a partir de polos geograficamente co-localizadas (Krugman 1991, Krugman \& Venables 1990, 1995, Baldwin et al. 2003), ou ainda, do grau de aglomeração e interação industrial da região que reduzem os custos de transporte e facilitam as transações comerciais entre seus estados (Marshall 1890, Arrow 1962, Romer 1986).

Do ponto de vista empírico, a investigação do crescimento regional e dos transbordamentos inter e intrarregionais concentram-se na utilização de modelos espaciais e gravitacionais de comércio, de modelos de equilíbrio geral computável (MEGC), e de modelos macroeconométricos. Baseando-se no modelo de comércio sob competição monopolística entre dois países com custos de transporte desenvolvido por Krugman (1980), os modelos gravitacionais têm como principal justificativa teórica à idéia de que os fluxos bilaterais de comércio são diretamente proporcionais à renda dos países e inversamente proporcionais à distância entre eles, em analogia à fórmula da atração gravitacional entre duas massas. Seguindo essa linha metodológica, Porto (2002) analisa os impactos do Mercosul nas regiões brasileiras com um modelo gravitacional expandido por dummies representativas para o Mercosul e regiões brasileiras. O autor conclui que os impactos mais sigficativos do comércio foram nas regiões Sul e Sudeste em relação às demais regiões brasileiras no período entre 1990 e 1998 . Portanto, o Mercosul poderia estar contribuindo para o agravamento das desigualdades regionais no Brasil.

Perobelli \& Haddad (2006b) encontram, entre outros resultados, uma heterogeneidade espacial no comércio interestadual do Brasil, com o cluster de alto comércio localizando-se na porção Centro-Sul do país, enquanto o cluster formado por estados com comércio abaixo da média dos vizinhos com o mesmo padrão localiza-se na região Norte. A análise intertemporal realizada por esses autores mostrou que tal padrão não se modificou ao longo do período analisado e concluem que caso esse padrão se mantenha, haverá um aumento das disparidades regionais no Brasil. 
Por fim, a partir de uma matriz interestadual de insumo-produto para os anos de 1996 e 2002, Perobelli et al. (2010) buscam identificar e calcular as interdependências inter-regionais brasileiras. Entre outros resultados, estes autores reportam que: (i) na região Norte, o estado do Pará, que tem uma base produtiva fortemente atrelada ao setor extrativo mineral, apresentou fraca integração espacial. Já o polo eletro eletrônico da zona franca de Manaus no Amazonas, mostrou-se relevante para o estado. Entretanto, seus efeitos de encadeamento para a própria região são incipientes e, portanto, não verificaram a distribuição de renda no contexto intrarregional; (ii) no Sudeste, o estado de São Paulo destaca-se com forte encadeamento e altos níveis de formação de renda para outros setores formando um círculo "virtuoso" para a economia paulista; (iii) no Sul do Brasil, identificaram resultados expressivos em termos de encadeamento e de desconcentração da interdependência produtiva e (v) no setor agrícola da região Centro-Oeste, houve um aumento do encadeamento com as regiões Norte e Nordeste no período analisado.

Por meio de modelos MEGC, Perobelli \& Haddad (2006a) argumentam que a contribuição do comércio para o desenvolvimento depende, dentre outros fatores, da natureza do setor exportador, da distribuição de seus benefícios e dos linkages dos setores exportadores com os demais setores da economia. Já Haddad et al. (2002) reportam que a integração econômica direcionada pelo governo brasileiro se mostra fortemente susceptível ao agravamento das desigualdades do país; o comércio, considerando aspectos intrarregionais pode estar ocasionando efeitos assimétricos, uma vez que seus benefícios dependem muito da natureza de sua base exportadora e que tais efeitos no Brasil mostraram-se importantes apenas para aqueles estados com melhor infraestrutura para o comércio.

Os modelos macroeconométricos buscam harmonia entre a coerência com a teoria econômica e critérios estatísticos. Esses modelos têm passado por uma série de mudanças nos últimos trinta anos, motivadas tanto pela evolução da teoria econômica e econométrica como pelas grandes transformações das relações econômicas entre países. Diversos estudos deram as suas contribuições nesse período. Os primeiros seguiam a tradicional abordagem da Cowles Commission, grandes modelos macroeconométricos com centenas de equações e distinção entre variáveis endógenas e exógenas eram estimados por mínimos quadrados, ou por métodos de variáveis instrumentais. Em seguida, Sims (1980) levantou sérias críticas sobre a identificação dos modelos de expectativas racionais e sobre a tradicional abordagem da Cowles Commission para utilização de modelos de equações simultâneas. Essa crítica impulsionou os estudos na direção da utilização de vetores auto-regressivos (VAR) para a modelagem macroeconométrica.

Os modelos Dynamic Stochastic General Equilibruium (DSGE), surgem a partir dos trabalhos de Kydland \& Prescott (1982), Long \& Plosser (1983) que utilizam um modelo de escolha intertemporal otimizadora por parte das famílias e firmas. Posteriormente, muitos modelos DSGE são aproximados por meio da utilização de um VAR restrito, como nos estudos de Smets e Wounters (2003) e Christiano et al. (2005).

No que se referem aos modelos econômicos regionais, estes são construídos e moldados a partir de seus congêneres nacionais e, até o presente, verificase que a metodologia macroeconométrica moderna tem sido subutilizada por pesquisadores da área de economia regional (Rickman 2010). Portanto, o tratamento macroeconométrico baseado nos modelos VAR, DSGE ou VAR restri- 
tos, pode contribuir com respostas e evidências empíricas sobre os problemas inerentes dessa área.

Uma primeira tentativa de análise dessas interdependências dentro do arcabouço de vetores auto-rregressivos pode ser encontrada em Kuszczak \& Murray (1986) que analisam o movimento internacional dos ciclos de negócios entre os principais países industrializados do G-7 com enfoque nas interações e transmissões regionais entre estados Unidos e Canadá com o resto do mundo. Os autores utilizam o Índice de Produção Industrial (IPI) como variável de atividade econômica, a inflação dada pelo índice de preços ao consumidor, oferta de moeda medida pelo M1 e a taxa de câmbio em uma frequência trimestral entre 1964 e 1984 e concluem que as variáveis do setor externo exercem uma influência forte e estatisticamente robusta sobre as economias do Canadá, estados Unidos e resto do mundo.

Em investigação sobre as ligações inter-regionais no crescimento da renda per capita, Carlino \& DeFina (1995) utilizam dados anuais para oito regiões norte-americanas entre 1929-1990 e modelos VAR. A partir da análise das funções de impulso resposta, os autores mostram que os choques na taxa de crescimento da renda per capita de uma determinada região têm fortes repercussões inter-regionais com respostas que tendem a ser geograficamente dispersas.

Cromwell (1992) analisa a existência de interações entre o estado da Califórnia e os seus vizinhos com vista a observar até que ponto um choque na atividade econômica deste se espalham para os seus estados vizinhos, por meio de modelos VAR e dados trimestrais entre 1947 e 1991 . O autor encontra, entre outros resultados, que a economia da Califórnia tem repercussões importantes em outros estados ocidentais, particularmente naqueles geograficamente mais próximos. E os maiores efeitos apresentaram-se no mercado de trabalho e na indústria.

Em estudo recente sobre as possíveis repercussões inter-regionais ocasionados por choques na atividade econômica entre as regiões da China, Groenewold et al. (2007) utilizam dados do Produto Interno Bruto (PIB) entre 1953 e 2003 e uma classificação de seis regiões. A partir de um modelo VAR restrito encontram, entre outros resultados, que as três regiões centrais, que formam o coração industrial chinês, Southeast, Changjiang River e Yellow River se mostraram fortemente interligadas apresentando fortes repercussões positivas. Por outro lado, a região Northeast é fracamente relacionada com as regiões vizinhas, afeta negativamente as regiões mais desenvolvidas, mas recebe transbordamentos positivos das regiões Southeast, Changjiang River e Yellow River.

Para o Brasil, Tatiwa \& Arruda (2011) mostram por meio de funções de impulso resposta de um modelo VAR que há uma forte interdependência da atividade industrial entre as regiões brasileiras e destas com o setor externo, na qual a região Sudeste apresenta os maiores e mais persistentes efeitos sobre as demais regiões. Apenas o Nordeste brasileiro apresentou impactos negativos, em termos de atividade industrial, sobre as demais regiões mostrando-se uma região com uma indústria ainda incipiente de fraca interação com as demais. Analisando os impactos do crescimento das exportações sobre a dinâmica industrial, os autores ressaltam que tais efeitos estão fortemente ligados ao perfil do setor exportador de cada região, uma vez que apenas o Sudeste reagiu positivamente, revelando a predominância das atividades agrícolas nas exportações das regiões Sul e Nordeste em detrimento da indústria exporta- 
dora de manufaturados presente no Sudeste brasileiro.

O presente estudo segue a linha dos modelos macroeconométricos aplicados em economia regional para averiguar, utilizando-se de modelos vetoriais dinâmicos com restrições no âmbito intrarregional, que estados se mostram mais importantes para a dinâmica industrial e em que regiões essas interações se mostram mais fortes. Além disso, será investigado como o crescimento das exportações repercute sobre a atividade da indústria e se existem assimetrias associadas ao perfil exportador dos estados.

\section{Base de Dados}

Para averiguar os impactos propostos nesse estudo, foram coletadas informações mensais em nível estadual, ${ }^{3}$ entre janeiro de 1996 e Fevereiro de 2010, ${ }^{4}$ sobre produção industrial, inflação e exportações, além da taxa de câmbio, considerada exógena nos modelos utilizados.

O Índice de Produção Industrial — Indústria Geral - (IPI) em nível estadual, calculado pelo Instituto Brasileiro de Geografia e Estatística (IBGE), foi utilizado como medida de atividade industrial. Devido à indisponibilidade de dados para o IPI de seus estados no período considerado, as regiões Norte e Centro-Oeste foram excluídas da análise.

A medida de inflação utilizada foi calculada a partir do Índice de Preços ao Consumidor Ampliado (IPCA) para as regiões metropolitanas das capitais dos estados brasileiros ${ }^{5}$ e disponibilizadas pelo IBGE no Sistema Nacional de Preços ao Consumidor (SNIPC). Vale ressaltar que a inflação por estado, embora pouco utilizada em trabalhos de economia regional, foi incorporada por ser uma importante variável de controle para as condições de oferta da economia. Entretanto o IPCA é o único índice de preços disponível na frequência mensal e no período analisado para os estados que compõem a amostra utilizada nesse estudo. Portanto, a inflação calculada por essa variável será utilizada como proxy da inflação local ao produtor. A inflação pode gerar incertezas em relação à oferta de um bem. Por um lado a curva de oferta de Lucas mostra que o produto pode ser influenciado pela diferença entre um índice de preços local e um geral, formado por expectativas sobre observações dos preços locais. Além disso, se os preços, principalmente de insumos industriais, sobem mais em um estado do que em outro a ponto de compensar custos de transportes, pode existir uma maior demanda de bens industriais no estado com menor inflação.

Os dados de comércio exterior por estado ${ }^{6}$ foram obtidos junto a Secretaria

\footnotetext{
${ }^{3}$ Os estados são Bahia, Ceará e Pernambuco no Nordeste; São Paulo, Rio de Janeiro e Minas Gerais no Sudeste e Paraná e Rio Grande do Sul no Sul.

${ }^{4}$ A economia brasileira passou por importantes transformações na condução de sua política macroeconômica nesse período, entre elas, a mudança de regime cambial e a implementação do regime de metas de inflação, em 1999, e a lei de responsabilidade fiscal em 2000. Além disso, a economia mundial enfrentou forte crise em 2008. O modelo proposto nesse estudo incorpora as variáveis inflação e oscilações na taxa de câmbio para controlar os efeitos de alterações nas condições de oferta da economia, na condução da política monetária e nas condições de comércio e fluxo internacional de capitais.

${ }^{5} \mathrm{O}$ IBGE disponibiliza tais dados para as regiões metropolitanas de Belém, Fortaleza, Recife, Salvador, Belo Horizonte, Rio de Janeiro, São Paulo, Curitiba e Porto Alegre, Brasília e município de Goiânia.

${ }^{6}$ Os dados de exportação e importação são referentes ao conceito FOB (freeonboard), designando uma modalidade de repartição de responsabilidade em que o exportador e o importador
} 
de Comercio Exterior (SECEX) do Ministério de Desenvolvimento Indústria e Comércio (MDIC). Vale destacar que esta variável foi devidamente deflacionada pelo Índice Geral de Preços — Disponibilidade Interna (IGP-DI).

Para subsidiar a análise econométrica e levantar fatos estilizados que possam contribuir para análises qualitativas dos resultados dos modelos propostos neste estudo, procedeu-se uma análise descritiva da dinâmica intrarregional sob a ótica das exportações e importações dos estados considerados. Inicialmente, analisou-se a evolução das participações percentuais das exportações e importações no produto interno bruto - PIB — de cada estado e do Brasil entre os anos de 1995 e 2009. Os dados estão sintetizados na Tabela 1.

Na região Nordeste percebe-se que a Bahia é o estado dessa região com maior inserção no comércio internacional com uma participação média das exportações e importações no PIB na ordem de $5.4 \%$ e $4.13 \%$, respectivamente. Já Pernambuco apresentou, em média, o nível de abertura menos representativo, com apenas $1.4 \%$ e $2.9 \%$ do PIB representado por exportações e importações, respectivamente. Vale destacar que, considerando a média do período, apenas Bahia apresentou superávit na balança comercial.

No Sudeste brasileiro destacaram-se os estados de São Paulo e Minas Gerais, com maiores participações médias das importações e exportações no PIB, respectivamente, na ordem de $6.3 \%$ e $7 \%$. Além disso, em termos médios, apenas a balança comercial mineira se mostrou superavitária com participação das exportações no PIB superior a média nacional.

No estado do Rio Grande do Sul as exportações e importações representaram, em média, $7.7 \%$ e $4.91 \%$ do PIB, respectivamente. As mesmas proporções no Paraná foram $7.5 \%$ e $5.46 \%$. Na região Sul todos os estados apresentaram participações de exportações e importações no PIB acima da média nacional.

Em seguida, analisou-se a participação das exportações e importações por setores de contas nacionais, ${ }^{7}$ quais sejam: bens de capital, bens intermediários, bens de consumo e combustíveis e lubrificantes. As informações estão sintetizadas na Tabela 2.

De forma geral, pode-se dizer que, em termos agregados, o setor de bens intermediários é o que apresenta a maior participação tanto nas exportações como nas importações de todos os estados. Além disso, verificou-se uma fraca participação das exportações dos estados brasileiros no setor de bens de capital.

Na região Nordeste pode-se destacar a forte participação dos bens de consumo não duráveis nas exportações de Pernambuco e Ceará, com contribuições na ordem de $37.4 \%$ e $59.4 \%$, respectivamente. Além disso, apenas o estado da Bahia obteve uma participação de insumos industriais na exportação superior à contribuição destes nas importações com $56 \%$ e $37 \%$, respectivamente. Por fim, vale destacar o fraco desempenho da região na exportação de bens de capital, categoria em que todos os estados apresentaram participação menor do que $4 \%$.

A região mais diversificada, segundo o critério dos setores de contas nacionais, foi o Sudeste brasileiro. O estado do Rio de Janeiro destacou-se na exportação de combustíveis e lubrificantes, com participação na ordem de 66\%. A

dividem os custos de segurança e transporte da mercadoria.

${ }^{7}$ Participação percentual em relação ao total de exportações e importações de cada estado. Utilizou-se a média dos anos 2005 a 2009. 
Tabela 1: Evolução da Participação das Exportações (EXP) e Importações (IMP) no PIB - Brasil e Estados Analisados (\%).

\begin{tabular}{|c|c|c|c|c|c|c|c|c|c|c|c|c|c|c|c|c|c|c|}
\hline \multirow{3}{*}{ Ano } & \multirow{2}{*}{\multicolumn{2}{|c|}{ Brasil }} & \multicolumn{6}{|c|}{ Nordeste } & \multicolumn{6}{|c|}{ Sudeste } & \multicolumn{2}{|c|}{ Sul } & & \\
\hline & & & \multicolumn{2}{|c|}{ Bahia } & \multicolumn{2}{|c|}{ Pernambuco } & \multicolumn{2}{|c|}{ Ceará } & \multicolumn{2}{|c|}{ São Paulo } & \multicolumn{2}{|c|}{ Rio de Janeiro } & \multicolumn{2}{|c|}{ Minas Gerais } & \multicolumn{2}{|c|}{ Rio Grande do Sul } & \multicolumn{2}{|c|}{ Paraná } \\
\hline & EXP & IMP & EXP & IMP & EXP & IMP & EXP & IMP & EXP & IMP & EXP & IMP & EXP & IMP & EXP & IMP & EXP & IMP \\
\hline 1995 & 7,20 & 7,73 & 7,17 & 5,17 & 3,29 & 4,55 & 2,82 & 5,18 & 6,97 & 10,34 & 2,77 & 6,26 & 9,31 & 4,70 & 9,66 & 5,62 & 9,30 & 6,23 \\
\hline 1996 & 6,13 & 6,84 & 5,60 & 4,31 & 1,59 & 3,82 & 2,43 & 5,20 & 6,09 & 9,45 & 2,17 & 5,88 & 7,37 & 3,63 & 8,95 & 5,26 & 8,90 & 5,17 \\
\hline 1997 & 6,09 & 7,05 & 5,04 & 4,55 & 1,59 & 3,91 & 2,01 & 4,21 & 5,86 & 9,38 & 1,78 & 5,48 & 8,29 & 4,37 & 9,06 & 5,55 & 9,18 & 6,55 \\
\hline 1998 & 5,59 & 6,31 & 4,72 & 3,85 & 1,46 & 3,69 & 1,89 & 3,22 & 5,62 & 8,62 & 1,77 & 4,58 & 8,48 & 3,98 & 7,98 & 6,14 & 7,44 & 7,15 \\
\hline 1999 & 4,93 & 5,05 & 3,76 & 3,49 & 1,02 & 2,83 & 1,90 & 2,94 & 5,16 & 6,85 & 1,43 & 3,81 & 6,81 & 3,12 & 6,63 & 4,34 & 6,37 & 5,99 \\
\hline 2000 & 5,01 & 5,07 & 4,03 & 4,65 & 0,98 & 3,21 & 2,38 & 3,45 & 5,34 & 6,91 & 1,33 & 3,61 & 6,32 & 2,62 & 6,79 & 4,73 & 6,66 & 7,10 \\
\hline 2001 & 4,86 & 4,64 & 4,06 & 4,38 & 1,06 & 3,24 & 2,45 & 2,89 & 5,16 & 6,18 & 1,63 & 3,60 & 5,34 & 2,64 & 6,75 & 4,30 & 7,31 & 6,77 \\
\hline 2002 & 4,09 & 3,20 & 3,98 & 3,09 & 0,91 & 2,39 & 1,89 & 2,20 & 3,94 & 3,88 & 2,14 & 3,15 & 4,97 & 1,97 & 6,05 & 3,35 & 6,45 & 3,77 \\
\hline 2003 & 4,31 & 2,84 & 4,79 & 2,85 & 1,05 & 2,02 & 2,34 & 1,66 & 3,99 & 3,51 & 2,58 & 2,61 & 5,00 & 1,63 & 6,45 & 3,36 & 6,54 & 3,18 \\
\hline 2004 & 4,98 & 3,24 & 5,14 & 3,82 & 1,18 & 1,72 & 2,34 & 1,55 & 4,84 & 4,21 & 3,15 & 2,85 & 5,64 & 1,68 & 7,18 & 3,84 & 7,68 & 3,29 \\
\hline 2005 & 5,52 & 3,43 & 6,59 & 3,69 & 1,57 & 1,61 & 2,28 & 1,44 & 5,25 & 4,19 & 3,32 & 2,71 & 7,02 & 2,04 & 7,26 & 4,64 & 7,92 & 3,57 \\
\hline 2006 & 5,82 & 3,86 & 7,02 & 4,64 & 1,41 & 1,85 & 2,08 & 2,37 & 5,75 & 4,62 & 4,17 & 2,65 & 7,29 & 2,26 & 7,53 & 5,07 & 7,33 & 4,38 \\
\hline 2007 & 6,04 & 4,53 & 6,76 & 4,94 & 1,40 & 2,76 & 2,28 & 2,80 & 5,73 & 5,36 & 4,82 & 3,22 & 7,61 & 2,70 & 8,50 & 5,76 & 7,64 & 5,58 \\
\hline 2008 & 6,53 & 5,7 & 7,16 & 5,19 & 1,33 & 3,49 & 2,12 & 2,59 & 5,75 & 6,62 & 5,45 & 4,20 & 8,65 & 3,71 & 9,22 & 7,28 & 8,51 & 8,13 \\
\hline 2009 & 4,72 & 3,94 & 5,11 & 3,41 & 1,05 & 2,53 & 1,64 & 1,87 & 3,91 & 4,66 & 3,82 & 3,29 & 6,80 & 2,56 & 7,06 & 4,39 & 5,91 & 5,06 \\
\hline Média & 5,45 & 4,90 & 5,39 & 4,13 & 1,39 & 2,91 & 2,19 & 2,90 & 5,29 & 6,32 & 2,82 & 3,86 & 6,99 & 2,91 & 7,67 & 4,91 & 7,54 & 5,46 \\
\hline
\end{tabular}

Fonte: Elaboração própria a partir dos dados do IBGE e SECEX/MDIC. 
Tabela 2: Participação das Exportações e Importações por Setores de Contas Nacionais (\%) (Média 2005 — 2009).

\begin{tabular}{|c|c|c|c|c|c|c|c|}
\hline & \multirow{2}{*}{ REGIÃO NORDESTE } & \multicolumn{2}{|c|}{ Bahia } & \multicolumn{2}{|c|}{ Pernambuco } & \multicolumn{2}{|c|}{ Ceará } \\
\hline & & EXP & IMP & EXP & IMP & EXP & IMP \\
\hline \multirow{2}{*}{ BENS DE CAPITAL } & Bens de Capital & 0,65 & 16,45 & 3,60 & 16,17 & 1,18 & 14,30 \\
\hline & Equipamentos de Transporte de uso industrial & 0,01 & 3,76 & 0,10 & 0,16 & 0,03 & 1,44 \\
\hline \multirow{3}{*}{ BENS INTERMEDIÁRIOS } & Alimentos e Bebidas destinadas a indústria & 9,24 & 5,06 & 14,92 & 13,15 & 0,46 & 12,22 \\
\hline & Insumos Industriais & 55,95 & 36,70 & 34,24 & 44,12 & 32,59 & 43,40 \\
\hline & Peças e Acessórios de Equipamentos de Transporte & 2,97 & 1,99 & 2,88 & 1,36 & 0,94 & 1,02 \\
\hline \multirow{2}{*}{ BENS DE CONSUMO } & Bens de consumo duráveis & 10,44 & 9,84 & 0,32 & 0,83 & 3,23 & 1,72 \\
\hline & Bens de Consumo não duráveis & 3,85 & 1,17 & 37,44 & 10,41 & 59,37 & 3,00 \\
\hline \multirow{3}{*}{ COMBUSTÍVEIS } & Combustíveis e Lubrificantes & 15,77 & 24,53 & 1,96 & 13,8 & 0,17 & 22,89 \\
\hline & REGIÃO SUDESTE & \multicolumn{2}{|c|}{ São Paulo } & \multicolumn{2}{|c|}{ Rio de Janeiro } & \multicolumn{2}{|c|}{ Minas Gerais } \\
\hline & & EXP & IMP & EXP & IMP & EXP & IMP \\
\hline \multirow{2}{*}{ BENS DE CAPITAL } & Bens de Capital & 16,91 & 32,46 & 5,53 & 15,55 & 2,56 & 24,08 \\
\hline & Equipamentos de Transporte de uso industrial & 12,59 & 0,37 & 1,88 & 2,4 & 1,4 & 6,13 \\
\hline \multirow{3}{*}{ BENS INTERMEDIÁRIOS } & Alimentos e Bebidas destinadas a indústria & 6,81 & 1,16 & 0,02 & 1,86 & 17,25 & 1,19 \\
\hline & Insumos Industriais & 24,24 & 32,23 & 14,39 & 24,65 & 65,46 & 33,86 \\
\hline & Peças e Acessórios de Equipamentos de Transporte & 11,48 & 11,45 & 2,44 & 11,11 & 2,77 & 11,87 \\
\hline \multirow{2}{*}{ BENS DE CONSUMO } & Bens de consumo duráveis & 4,79 & 1,92 & 1,64 & 4,35 & 4,93 & 6,14 \\
\hline & Bens de Consumo não duráveis & 17,08 & 9,07 & 2,43 & 7,92 & 5,52 & 3,76 \\
\hline \multirow[t]{3}{*}{ COMBUSTÍVEIS } & Combustíveis e Lubrificantes & 3,00 & 11,32 & 65,74 & 31,96 & 0,05 & 12,84 \\
\hline & \multirow{2}{*}{ REGIÃO SUL } & \multicolumn{2}{|c|}{ Rio Grande do Sul } & \multicolumn{2}{|c|}{ Paraná } & & \\
\hline & & EXP & IMP & EXP & IMP & EXP & IMP \\
\hline \multirow{2}{*}{ BENS DE CAPITAL } & Bens de Capital & 11,45 & 12,19 & 6,22 & 21,92 & - & - \\
\hline & Equipamentos de Transporte de uso industrial & 1,13 & 5,02 & 3,67 & 0,4 & - & - \\
\hline \multirow{3}{*}{ BENS INTERMEDIÁRIOS } & Alimentos e Bebidas destinadas a indústria & 10,96 & 1,39 & 20,98 & 2,84 & - & - \\
\hline & Insumos Industriais & 35,90 & 25,45 & 31,88 & 30,56 & - & - \\
\hline & Peças e Acessórios de Equipamentos de Transporte & 5,34 & 4,21 & 8,07 & 13,3 & - & - \\
\hline \multirow{2}{*}{ BENS DE CONSUMO } & Bens de consumo duráveis & 2,83 & 5,78 & 9,01 & 7,14 & - & - \\
\hline & Bens de Consumo não duráveis & 26,82 & 3,29 & 17,47 & 5,53 & - & - \\
\hline COMBUSTÍVEIS & Combustíveis e Lubrificantes & 4,35 & 42,64 & 0,98 & 18,30 & - & - \\
\hline
\end{tabular}


economia mineira foi a única com contribuição dos insumos industriais nas exportações superiores àquelas presentes nas importações, com $65.5 \%$ e $33.9 \%$, respectivamente. Por fim, a indústria de bens de capital paulista apresentou a maior participação nas exportações entre todas as regiões analisadas, cerca de $17 \%$, revelando que o polo industrial paulista tem atuado em setores de alto valor agregado.

Por fim, a região Sul destacou-se por uma maior participação de insumos industriais nas exportações do que nas importações em todos os estados analisados, além de uma forte participação de combustíveis em suas importações. Vale destacar ainda a forte participação dos bens de consumo não duráveis nas exportações de Rio Grande do Sul e Paraná.

Além disso, sabe-se que no acompanhamento das exportações e importações por grau de elaboração do produto, o Brasil adota a classificação por fator agregado. Nesse conceito, o produto é classificado como básico ou industrializado, sendo este último grupo subdividido em semimanufaturado e manufaturado. Por fim, procedeu-se também uma análise descritiva dos perfis de composição de exportações e importações utilizando a referida classificação para os estados brasileiros. Os resultados estão sintetizados na Tabela 3.

Tabela 3: Composição de Exportações e Importações (por Fator Agregado) por Estado (\%).

\begin{tabular}{|c|c|c|c|c|c|c|}
\hline \multirow[t]{2}{*}{ Estados/Setores } & \multicolumn{2}{|c|}{ Básicos } & \multicolumn{2}{|c|}{$\begin{array}{l}\text { Semimanu- } \\
\text { faturados }\end{array}$} & \multicolumn{2}{|c|}{ Manufaturados } \\
\hline & EXP & IMP & EXP & IMP & EXP & IMP \\
\hline Bahia & 15,90 & 26,20 & 26,10 & 2,40 & 58,00 & 71,40 \\
\hline Pernambuco & 16,70 & 14,90 & 29,30 & 4,10 & 54,00 & 81,00 \\
\hline Ceará & 37,00 & 29,30 & 16,30 & 2,10 & 46,70 & 68,60 \\
\hline São Paulo & 6,90 & 10,40 & 8,70 & 2,80 & 84,40 & 86,80 \\
\hline Rio de Janeiro & 37,80 & 30,50 & 4,80 & 1,30 & 57,40 & 68,20 \\
\hline Minas Gerais & 45,30 & 16,80 & 23,40 & 6,00 & 31,30 & 77,20 \\
\hline Rio Grande do Sul & 35,40 & 30,90 & 10,70 & 5,60 & 53,90 & 63,50 \\
\hline Paraná & 41,70 & 20,60 & 12,10 & 5,60 & 46,20 & 73,80 \\
\hline \multicolumn{7}{|c|}{$\begin{array}{l}\text { Fonte: Elaboração própria a partir dos dados da SECEX/MDIC. Nota: Os básicos são } \\
\text { aqueles que guardam suas características próximas ao estado em que são encontrados } \\
\text { na natureza, ou seja, com um baixo grau de elaboração. São exemplos desse grupo } \\
\text { minérios, produtos agrícolas (café em grão, soja em grão, carne in natura, milho em } \\
\text { grão, trigo em grão, etc.). Os produtos semimanufaturados são aqueles que ainda não } \\
\text { estão em sua forma definitiva de uso, quer final quer intermediário, pois deverão } \\
\text { passar por outro processo produtivo para se transformarem em produto } \\
\text { Manufaturado (ex.: açúcar em bruto } \Rightarrow \text { açúcar refinado; óleo de soja em bruto } \Rightarrow \text { óleo } \\
\text { de soja em refinado; produtos semimanufaturados de ferro/aço } \Rightarrow \text { laminados planos; } \\
\text { celulose } \Rightarrow \text { papel, etc.). }\end{array}$} \\
\hline
\end{tabular}

Em termos gerais, pode-se destacar a participação majoritária dos manufaturados na composição das importações para todos os estados analisados. Considerando as exportações, percebe-se uma maior participação dos básicos no estado de Minas Gerais, com $45.3 \%$ e dos manufaturados em São Paulo, com $84.40 \%$. No Nordeste, o estado da Bahia destaca-se com $58 \%$ de sua pauta de exportações baseadas em manufaturados, enquanto que, na região Sul, o Rio Grande do Sul apresenta-se com 53.90\% de manufaturados. 


\section{Aspectos Metodológicos}

De acordo com Lutkepohl (2005), um modelo vetorial auto-regressivo com $p$ defasagens $\operatorname{VAR}(\mathrm{p})$, pode ser expresso da seguinte forma:

$$
y_{t}=v+A_{1} y_{t-1}+\ldots+A_{p} y_{t-p}+u_{t}
$$

Na qual $y_{t}$ é um vetor $(k \times 1)$ de variáveis endógenas, $A_{i}$ é uma matriz $(k \times k)$ de coeficientes fixos e $v$ um vetor $(k \times 1)$ de termos de intercepto. A matriz $A$ incorpora os efeitos defasados existentes. Finalmente, $u_{t}$ é um vetor $(k \times 1)$ de erros que se comportam como ruídos brancos (White noise); ou seja, $E\left(u_{t}\right)=0$, $E\left(u_{t} u_{t}^{\prime}\right)=\Sigma_{u}$ e $E\left(u_{t} u_{s}^{\prime}\right)=0$ para $s \neq t$. As restrições sobre os coeficientes desse modelo podem ser representadas da seguinte forma. Primeiro, reescreve-se o VAR como,

$$
Y=B Z+U
$$

Onde $Y=\left[y_{1}, \ldots, y_{T}\right] ; Z=\left[Z_{0}, \ldots, Z_{T-1}\right] \operatorname{com} Z_{t}^{\prime}=\left[\begin{array}{lll}1 & y_{1} \ldots y_{t-p+1}\end{array}\right] ; B=\left[v, A_{1}, \ldots\right.$ , $\left.A_{p}\right]$ e $U=\left[u_{1}, \ldots, u_{T}\right]$.

Suponha uma restrição linear para B que têm a forma

$$
\beta=\operatorname{vec}(B)=R \gamma+r
$$

Onde $\beta=v e c(B)$ é um vetor $(K(K p+1) \times 1)$, $R$ é uma matriz $(K(K p+1) \times M)$ conhecida de posto $M, \gamma$ é um vetor $(M \times 1)$ de parâmetros desconhecidos e $r$ é um vetor $(K(K p+1) \times 1)$ de constantes conhecidas. Embora não seja convencional, a representação encontrada em 3 permite a imposição de restrições por meio de uma simples reparametrização do modelo original. Substituindo $\beta=\operatorname{vec}(B)$ em 2 tem-se

$$
\begin{gathered}
y=\operatorname{vec}(Y)=\left(Z^{\prime} \otimes I_{K}\right) \operatorname{vec}(B)+\operatorname{vec}(U) \\
=\left(Z^{\prime} \otimes I_{K}\right)(R \gamma+r)+u \\
z=\left(Z^{\prime} \otimes I_{K}\right) R \gamma+u
\end{gathered}
$$

Onde $z=y-\left(Z^{\prime} \otimes I_{K}\right) r, u=v e c(U)$ e $\otimes$ denota o produto de Kronecker. Essa especificação é bastante conveniente por permitir a derivação dos estimadores e suas propriedades como no modelo VAR irrestrito. Seja $\Sigma_{u}$ a matriz de covariância de $u_{t}$, o vetor $\hat{\gamma}$ obtido na minimização de

$$
S(\gamma)=u^{\prime}\left(I_{T} \otimes \Sigma_{u}^{-1}\right) u=\left[z-\left(Z^{\prime} \otimes I_{K}\right) R \gamma\right]\left(I_{T} \otimes \Sigma_{u}^{-1}\right)\left[z-\left(Z^{\prime} \otimes I_{K}\right) R \gamma\right]
$$

Com respeito à $\gamma$, mostra-se que,

$$
\hat{\gamma}=\gamma+\left[R^{\prime}\left(Z Z^{\prime} \otimes \Sigma_{u}^{-1}\right) R\right]^{-1} R^{\prime}\left(I_{K p+1} \otimes \Sigma_{u}^{-1}\right) \operatorname{vec}\left(U Z^{\prime}\right)
$$

Esse estimador é comumente chamado de mínimos quadrados generalizados (GLS), pois minimiza a soma dos erros dos quadrados dos erros generalizados, $S(\gamma)$, em vez de apenas a soma dos quadrados dos erros $u^{\prime} u$. Lutkepohl (2005) mostra que quando há restrições nos parâmetros do VAR, o estimador 
de GLS é assintoticamente mais eficiente do que o de mínimos quadrados multivariados (LS) e que, nessa situação, o primeiro é preferível a este. O autor mostra ainda que, sob hipóteses gaussianas, o estimador de GLS é equivalente ao de máxima verossimilhança (MV).

Entretanto, o estimador $\hat{\gamma}$ apresenta limitações para a sua operacionalização uma vez que, na prática, ele requer o conhecimento de $\Sigma_{u}$. Como normalmente não se tem esta informação, deve-se utilizar um estimador para $\Sigma_{u}$. Portanto, usando uma estimativa consistente $\bar{\Sigma}_{u}$ para $\Sigma_{u}$ e substituindo-a em 6, obtém-se o chamado GLS estimável (EGLS) na forma,

$$
\hat{\gamma}=\left[R^{\prime}\left(Z Z^{\prime} \otimes \bar{\Sigma}_{u}^{-1}\right) R\right]^{-1} R^{\prime}\left(Z \otimes \bar{\Sigma}_{u}^{-1}\right) z
$$

Os multiplicadores dinâmicos de um sistema de variáveis, ou seja, suas funções de impulso resposta são dadas por:

$$
\begin{gathered}
y_{t}=\mu+\sum_{i=0}^{\infty} \Phi_{i} u_{t-i} \operatorname{com} \Phi_{0}=I_{K} \quad \mathrm{e} \\
y_{t}=\mu+\sum_{i=0}^{\infty} \Theta_{i} \omega_{t-i}
\end{gathered}
$$

Onde $\mu=E\left(y_{t}\right), \Theta_{i}=\Phi_{i} P, \omega_{t}=P^{-1} u_{t}$ e $P$ é uma decomposição de Choleski triangular inferior de $\Sigma_{u}$ tal que $\Sigma_{u}=P P^{\prime}$. Portanto, $\Sigma_{\omega}=E\left(\omega_{t} \omega_{t}^{\prime}\right)=I_{K}$.

Onde $\Phi_{i}$ e $\Theta_{i}$ são desconhecidos e serão calculados a partir dos parâmetros estimados do VAR e da matriz de covariância estimada. Para derivar a distribuição assintótica de $\Phi_{i}$ e $\Theta_{i}$ suponha apenas que os $\Phi_{i}$ 's são obtidos a partir dos coeficientes $A_{1}, \ldots, A_{p}$ de maneira recursiva a partir de,

$$
\Phi_{j}=\sum_{j=1}^{i} \Phi_{i-j} A_{j}, i=1,2, \ldots
$$

Começando com $\Phi_{0}=I_{K}$ e definindo $A_{j}>0$ para $j>p$, os $\Theta_{i}$ 's são obtidos para $A_{1}, \ldots, A_{p}$ e $\Sigma_{u}$ na forma $\Theta_{i}=\Phi_{i} P$, onde $P$ assume a especificação supracitada. Além disso, os respectivos impulsos resposta acumulados serão ${ }^{8}$

$$
\begin{gathered}
\Psi_{n}=\sum_{i=0}^{n} \Phi_{i}, \Psi_{\infty}=\sum_{i=0}^{\infty} \Phi_{i}=\left(I_{K}-A_{1}-A_{2}-\ldots-A_{p}\right)^{-1}, \quad \text { se existir } \\
\Xi_{n}=\sum_{i=0}^{n} \Theta_{i}, \quad \Xi_{\infty}=\sum_{i=0}^{\infty} \Theta_{i}=\left(I_{K}-A_{1}-A_{2}-\ldots-A_{p}\right)^{-1} P, \quad \text { se existir }
\end{gathered}
$$

A distribuição assintótica é demonstrada de uma maneira suficientemente geral a ponto de acomodar o caso em análise neste estudo. Agora os impulsos resposta são calculados a partir dos estimadores restritos de $A_{1}, \ldots, A_{p}$. Como mostra Lutkepohl (2005), as propriedades assintóticas de tais funções são as mesmas observadas no caso irrestrito e na prática, seus intervalos de confiança são gerados por métodos de bootstrap.

\footnotetext{
${ }^{8}$ Para demonstração e detalhes sobre a distribuição assintótica ver a proposição 3.6 em Lutkepohl (2005).
} 


\section{Análise e Discussão dos Resultados}

Para elaborar e estimar o modelo proposto neste estudo foram realizados inicialmente testes de raiz unitária nas variáveis utilizadas. ${ }^{9}$ Esses testes indicaram que todas as taxas de crescimento das variáveis utilizadas são estacionárias aos níveis usuais de significância conforme Tabela 4 abaixo.

Portanto, será utilizado um modelo vetorial dinâmico com restrições ${ }^{10}$ nos parâmetros em nível estadual para cada região. De acordo com o critério de informação de Schwarz, o VAR neste estudo deve ser especificado com apenas uma defasagem. ${ }^{11}$ Portanto, os modelos considerados nesa aplicação têm a seguinte especificação:

$$
y_{t}=v+A y_{t-1}+B x_{t-1}+u_{t}
$$

Onde $y_{t}$ é um vetor $(9 \times 1)$ que contém informações de atividade industrial, crescimento das exportações e inflação para Bahia, Pernambuco e Ceará, no Nordeste, São Paulo, Rio de Janeiro e Minas Gerais, no Sudeste. Para a região Sul tal vetor será $(6 \times 1)$ uma vez que se tem informações apenas para Rio Grande do Sul e Paraná. $x_{t-1}$ representa as oscilações cambiais, consideradas exógenas aos estados.

Dessa forma, tem-se um sistema para cada região com a dinâmica industrial dos estados sendo modelada em função: a) dela mesma defasada, para captar a persistência da atividade industrial passada no presente, uma vez que o que se produz hoje é em parte função do que foi produzido em período anterior; b) em função do crescimento industrial dos demais estados da região defasados para incorporar as repercussões objeto desse estudo; c) em função do crescimento das exportações do próprio estado e dos demais defasados, em virtude dos efeitos explicados no modelo KDT, para captar as transmissões destas sobre a dinâmica industrial e d) em função da inflação defasada, que atua como variável de controle das condições do lado da oferta. A restrição do sistema está na ausência da oscilação cambial na equação da dinâmica industrial, uma vez que os efeitos desta estão incorporados na variação das exportações e da inflação.

A equação de crescimento das exportações será função da atividade industrial do próprio estado e dos vizinhos da mesma região defasadas, também em virtude das relações presentes no modelo KDT; da variação das exportações no próprio estado e dos demais defasados captando a persistência e possíveis efeitos de concorrência ou de complementaridade nelas; da inflação do próprio estado e de seus vizinhos defasadas para controlar possíveis efeitos de concorrência de preços sobre a importação e a exportação interestaduais; e da variação na taxa de câmbio, aqui considerada exógena, que é uma variável fundamental na determinação das exportações.

Por fim, a inflação é modelada como função das variáveis de atividade do próprio estado e dos vizinhos defasadas, nos moldes de uma relação de oferta; das taxas de crescimento das exportações defasadas, incorporando as repercussões das variações das exportações sobre a inflação e, por fim, da taxa

\footnotetext{
${ }^{9}$ DLNIPI é a taxa de crescimento da produção industrial, DLNEXP é a taxa de crescimento das exportações, IPC é a inflação medida pelo IPCA e DCAMBIO é a taxa de variação cambial.

${ }^{10}$ Vale ressaltar que as restrições utilizadas neste exercício foram aplicadas apenas na variável exógena, que entra apenas nas equações de crescimento das exportações e da taxa de inflação.

${ }^{11}$ Depois de estimado foi realizada análise dos resíduos do modelo. De acordo com esse processo, os erros estimados se mostraram não autocorrelacionados.
} 
Tabela 4: Testes de Raiz Unitária - Modelo por estado.

\begin{tabular}{|c|c|c|c|c|c|c|c|c|c|}
\hline & Região & & Nordest & & & Sudeste & & & Sul \\
\hline Variável & Estado & Bahia & Ceará & Pernambuco & São Paulo & Rio de Janeiro & Minas Gerais & Paraná & Rio Grande do Sul \\
\hline \multirow[b]{2}{*}{ DLNIPI } & Intercepto & $\begin{array}{c}-7,66^{*} \\
(0,00)\end{array}$ & $\begin{array}{c}-3,90^{*} \\
(0,00)\end{array}$ & $\begin{array}{c}-6,84^{*} \\
(0,00)\end{array}$ & $\begin{array}{c}-3,01^{*} \\
(0,03)\end{array}$ & $\begin{array}{c}-4,69^{*} \\
(0,00)\end{array}$ & $\begin{array}{c}-3,39^{*} \\
(0,01)\end{array}$ & $\begin{array}{c}-6,79^{*} \\
(0,00)\end{array}$ & $\begin{array}{c}-4,60^{*} \\
(0,00)\end{array}$ \\
\hline & Intercepto e Tendência & $\begin{array}{c}-7,63^{*} \\
(0,00)\end{array}$ & $\begin{array}{c}-3,87^{*} \\
(0,01)\end{array}$ & $\begin{array}{c}-7,12^{*} \\
(0,00)\end{array}$ & $\begin{array}{r}-3,02 \\
(0,13)\end{array}$ & $\begin{array}{r}-4,88 \\
(0,00)\end{array}$ & $\begin{array}{c}-3,35^{*} \\
(0,00)\end{array}$ & $\begin{array}{c}-6,77^{*} \\
(0,00)\end{array}$ & $\begin{array}{c}-4,58^{*} \\
(0,00)\end{array}$ \\
\hline \multirow[b]{2}{*}{ DLNEXP } & Intercepto & $\begin{array}{c}-21,31^{*} \\
(0,00)\end{array}$ & $\begin{array}{c}-15,58 \\
(0,00)\end{array}$ & $\begin{array}{c}-9,77^{*} \\
(0,00)\end{array}$ & $\begin{array}{c}-2,91^{*} \\
(0,04)\end{array}$ & $\begin{array}{c}-20,61^{*} \\
(0,00)\end{array}$ & $\begin{array}{c}-12,86^{*} \\
(0,00)\end{array}$ & $\begin{array}{c}-10,77^{*} \\
(0,00)\end{array}$ & $\begin{array}{c}-5,20^{*} \\
(0,00)\end{array}$ \\
\hline & Intercepto e Tendência & $\begin{array}{c}-21,24^{*} \\
(0,00)\end{array}$ & $\begin{array}{r}-15,54^{*} \\
(0,00)\end{array}$ & $\begin{array}{c}-9,78^{*} \\
(0,00)\end{array}$ & $\begin{array}{c}-2,95^{* *} \\
(0,00)\end{array}$ & $\begin{array}{c}-20,55^{*} \\
(0,00)\end{array}$ & $\begin{array}{r}-12,82 \\
(0,00)\end{array}$ & $\begin{array}{c}-10,73^{*} \\
(0,00)\end{array}$ & $\begin{array}{c}-5,23^{*} \\
(0,00)\end{array}$ \\
\hline \multirow[b]{2}{*}{ IPC } & Intercepto & $\begin{array}{c}-7,60^{*} \\
(0,00)\end{array}$ & $\begin{array}{c}-6,79^{*} \\
(0,00)\end{array}$ & $\begin{array}{c}-7,64^{*} \\
(0,00)\end{array}$ & $\begin{array}{c}-6,98^{*} \\
(0,00)\end{array}$ & $\begin{array}{c}-7,42^{*} \\
(0,00)\end{array}$ & $\begin{array}{c}-7,69^{*} \\
(0,00)\end{array}$ & $\begin{array}{c}-8,20^{*} \\
(0,00)\end{array}$ & $\begin{array}{c}-6,80^{*} \\
(0,00)\end{array}$ \\
\hline & Intercepto e Tendência & $\begin{array}{c}-7,57^{*} \\
(0,00) \\
\end{array}$ & $\begin{array}{c}-6,78^{*} \\
(0,00) \\
\end{array}$ & $\begin{array}{c}-7,60^{*} \\
(0,00)\end{array}$ & $\begin{array}{c}-6,97^{*} \\
(0,00)\end{array}$ & $\begin{array}{c}-7,43^{*} \\
(0,00)\end{array}$ & $\begin{array}{c}-7,68^{*} \\
(0,00)\end{array}$ & $\begin{array}{c}-8,23^{*} \\
(0,00)\end{array}$ & $\begin{array}{c}-6,84^{*} \\
(0,00)\end{array}$ \\
\hline \multirow[b]{3}{*}{ DLNCAMBIO } & & & & & Brasil & & & & \\
\hline & Intercepto & $\begin{array}{c}-8,05^{*} \\
(0,00)\end{array}$ & & & & & & & \\
\hline & Intercepto e Tendência & $\begin{array}{l}-8,28^{*} \\
(0,00)\end{array}$ & & & & & & & \\
\hline
\end{tabular}

Fonte: Elaborado pelo autor a partir dos resultados do teste ADF. Valor p entre parênteses. ${ }^{*}$ Estacionárias aos níveis usuais de Significância. **Estacionárias a $10 \%$. 
de câmbio, considerada exógena, que reflete o repasse cambial para a inflação. Assim, o sistema tem a estrutura:

$$
\begin{aligned}
D L N I P I_{i t}= & f\left(D L N I P I_{i t-1}, D L N I P I_{j t-1}, D L N E X P_{i t-1},\right. \\
& \left.D L N E X P_{j t-1}, I P C_{i t-1}, I P C_{j t-1}\right) \\
D L N E X P_{i t}= & f\left(D L N I P I_{i t-1}, D L N I P I_{j t-1}, D L N E X P_{i t-1},\right. \\
& \left.D L N E X P_{j t-1}, I P C_{i t-1}, I P C_{j t-1}, D C A M B I O_{t-1}^{*}\right) \\
I_{P C} C_{i t}= & f\left(D L N I P I_{i t-1}, D L N I P I_{j t-1}, D L N E X P_{i t-1},\right. \\
& \left.D L N E X P_{j t-1}, I P C_{i t-1}, I P C_{j t-1}, D C A M B I O_{t-1}^{*}\right)
\end{aligned}
$$

Onde $i$ e $j$ denotam Bahia, Pernambuco e Ceará, no modelo para a região Nordeste; São Paulo, Rio de Janeiro e Minas Gerais, para o Sudeste e Rio Grande do Sul e Paraná, na aplicação para o Sul do Brasil; com $i \neq j$.

As repercussões intrarregionais investigadas neste trabalho serão observadas a partir da análise das funções das funções de impulso reposta ${ }^{12}$ calculadas a partir dos parâmetros estimados por EGLS do VAR restrito. Para identificar efeitos permanentes de tais repercussões, será utilizado uso do impulso resposta acumulado. O procedimento de bootstrap para a construção de intervalos de confiança apresentados por Hall (1992) será utilizado.

Inicialmente analisam-se as transmissões intrarregionais via impactos da atividade industrial entre os estados de cada região e em seguida, observam-se as respostas da dinâmica industrial intrarregional a choques no crescimento das exportações estaduais.

\subsection{Choques na Atividade Industrial}

Considerando inicialmente o Nordeste, a Figura 1 destaca as respostas da atividade industrial de Ceará e Pernambuco a choques no crescimento da indústria baiana. Percebe-se que os dois estados reagem positivamente e de forma imediata a tal choque tendo o estado de Pernambuco apresentado uma maior resposta. A resposta acumulada indica ainda que os efeitos permanentes sejam 33.3\% maiores em Pernambuco.

Nas mesmas condições, se o choque ocorresse em Pernambuco, tanto Bahia como Ceará respondem negativamente e, o último, de forma mais duradoura. Há de se destacar que o estado da Bahia se mostrou mais fortemente afetado, de acordo com a Figura 2. Caso o mesmo choque fosse verificado no Ceará, percebe-se que Pernambuco responderia positivamente de forma imediata enquanto que a atividade industrial da Bahia cairia durante o primeiro mês, crescendo a partir daí até que o choque se dissipe como mostra a Figura 3.

Portanto, há indícios de que a dinâmica industrial da região Nordeste é conduzida pelo estado da Bahia, uma vez que este apresentou os maiores e mais duradouros efeitos nos demais estados da região. Verifica-se também que os choques na taxa de crescimento da produção industrial da Bahia são os únicos que repercutem positivamente na dinâmica industrial de todos os outros estados dessa região.

\footnotetext{
${ }^{12}$ Serão apresentados na forma impulso $\rightarrow$ resposta e Accumulated impulso $\rightarrow$ resposta, para as acumuladas.
} 
DLNIPI_BA $\rightarrow D_{D L N I P I} P E$

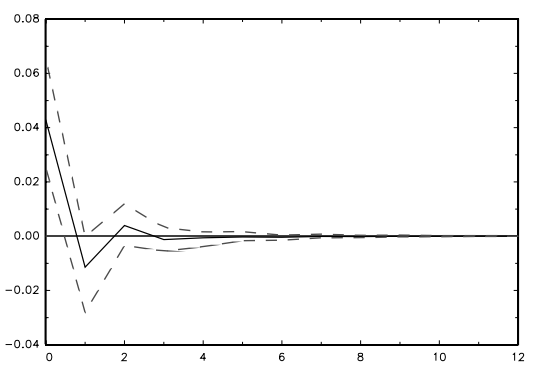

accumulated DLNIPI_BA $\rightarrow$ DLNIPI_PE

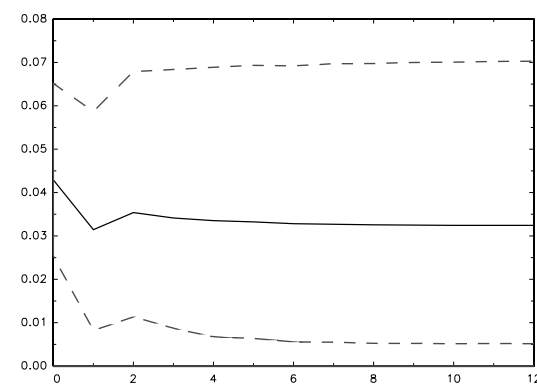

DLNIPI_BA $\rightarrow D L N I P I+C E$

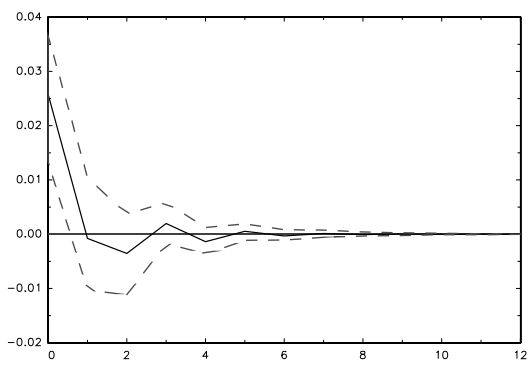

accumulated ULNIHI_BA $\rightarrow$ ULNIHI_CE

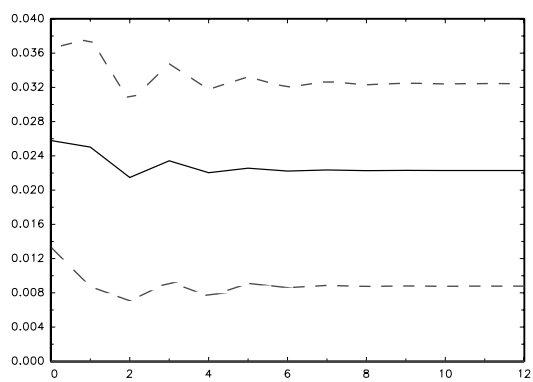

Fonte: Elaboração Própria a partir do modelo estimado.

Figura 1: Respostas da Atividade Industrial de Pernambuco e Ceará a choques na dinâmica Industrial da Bahia.
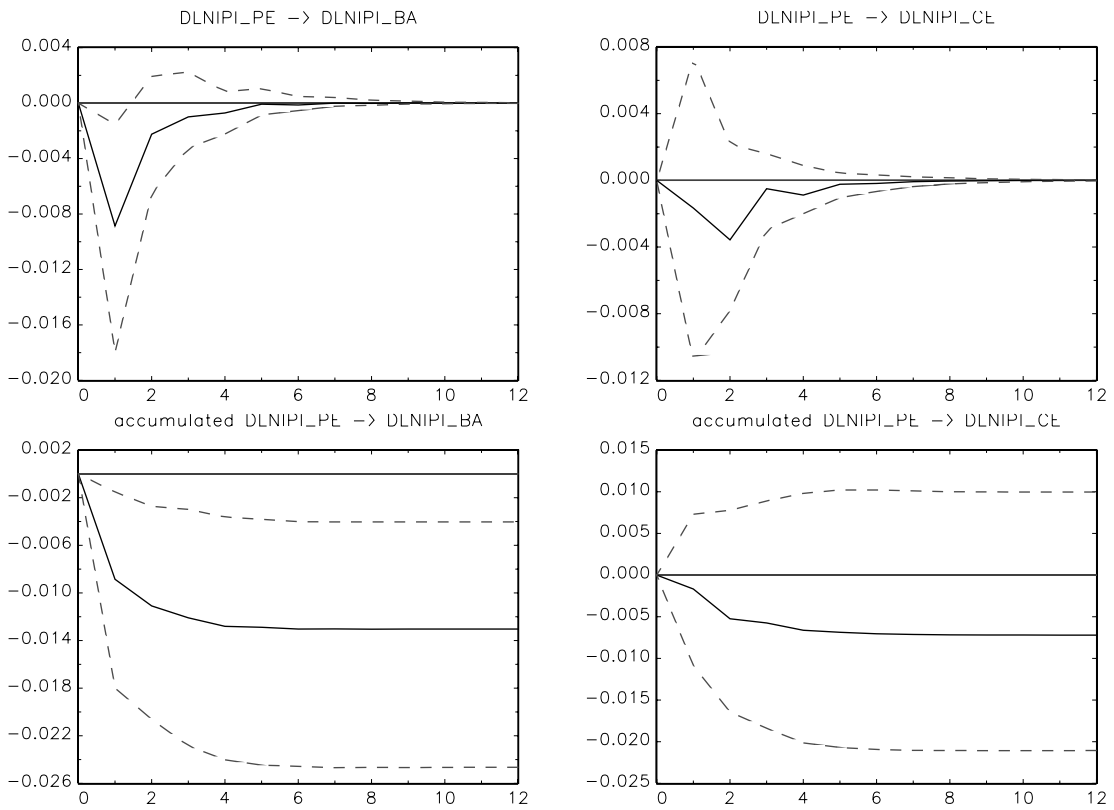

Fonte: Elaboração Própria a partir do modelo estimado.

Figura 2: Respostas da Atividade Industrial de Bahia e Ceará a choques na dinâmica Industrial de Pernambuco. 
Esses resultados podem refletir uma falta de sincronização ou assimetria dos ciclos industriais do Ceará e de Pernambuco, ou ainda, a presença de possíveis efeitos complementares gerados pela atividade industrial da Bahia e do Ceará e efeitos substituição gerados por Pernambuco. Em outras palavras, o crescimento industrial da Bahia e do Ceará parece gerar um aumento na demanda por insumos em outros estados, proporcionando um maior spread effect. Já um choque semelhante na atividade industrial de Pernambuco parece gerar um efeito substituição, revelando certa rivalidade com a atividade industrial do Ceará e da Bahia, promovendo, assim, um backwash effect mais forte. Essas evidências corroboram as apresentadas por Perobelli \& Haddad (2006a) que destacam a forte contribuição do estado da Bahia para os fluxos inter e intrarregionais.
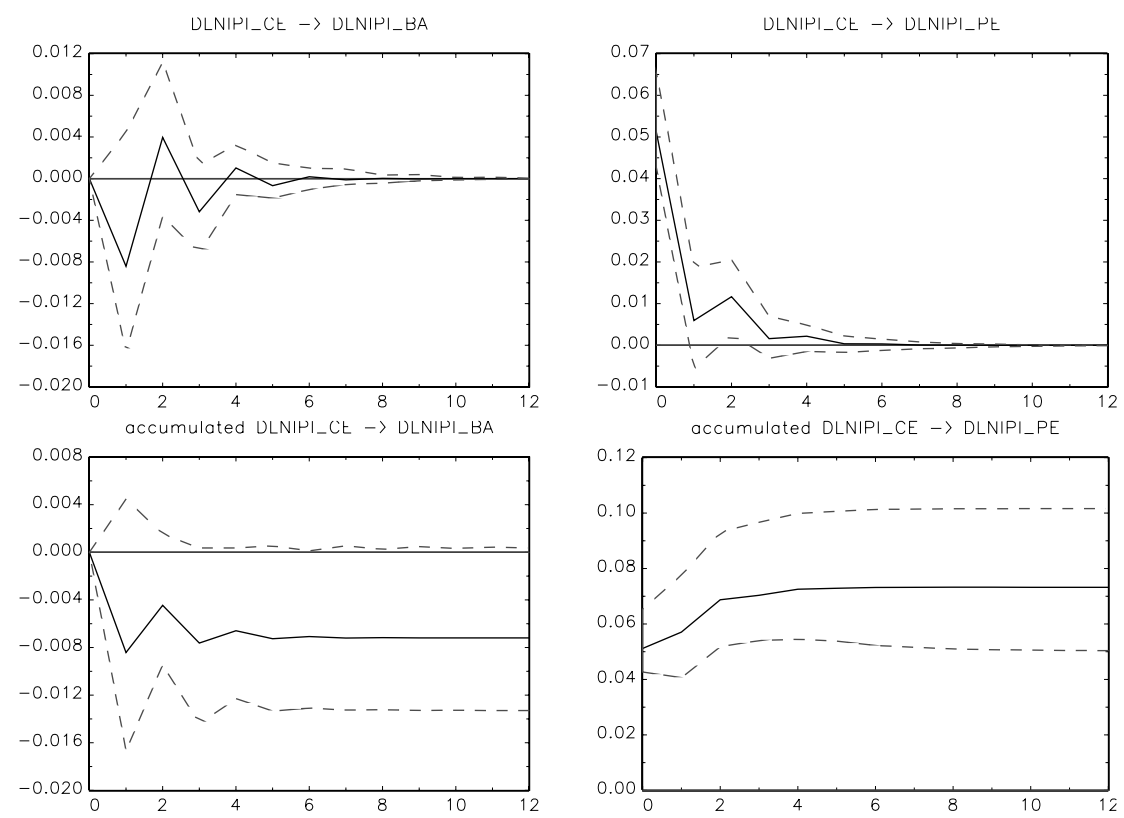

Fonte: Elaboração Própria a partir do modelo estimado.

Figura 3: Respostas da Atividade Industrial de Bahia e Pernambuco a choques na dinâmica Industrial do Ceará.

Em seguida, avaliou-se o comportamento intrarregional da dinâmica industrial da região Sudeste do Brasil e verificou-se que tanto Minas Gerais como o Rio de Janeiro reagem de forma positiva e imediata a choques na atividade industrial de São Paulo com maior impacto no primeiro, de acordo com a Figura 4. Os efeitos permanentes, representados pelas respostas acumuladas, são $42.2 \%$ maiores sobre o estado de Minas Gerais.

Em condições semelhantes, um choque na indústria do Rio de Janeiro provoca uma reação positiva e imediata em Minas Gerais e uma reação negativa em São Paulo durante o primeiro mês, reagindo a seguir até dissipar-se como mostra a Figura 5. Tal resultado também pode indicar um comportamento assimétrico ou dessincronizado do ciclo industrial do Sudeste brasileiro.

A Figura 6 apresenta a mesma análise considerando que o choque ocorre na atividade industrial de Minas Gerais. Observa-se uma reação positiva de São Paulo durante o primeiro mês passando a cair até convergir dois meses 
DLNIPI SP $\rightarrow$ DINIPI RJ
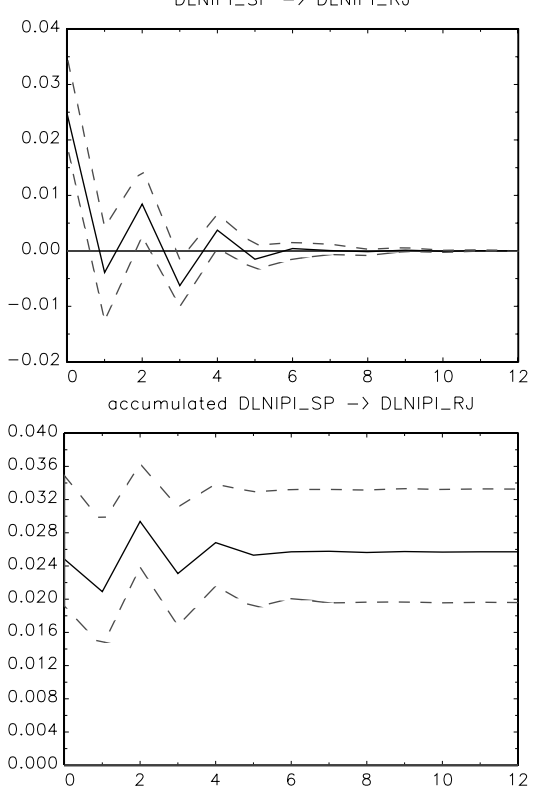

DLNIHLSH $\rightarrow$ DLNIHILMG

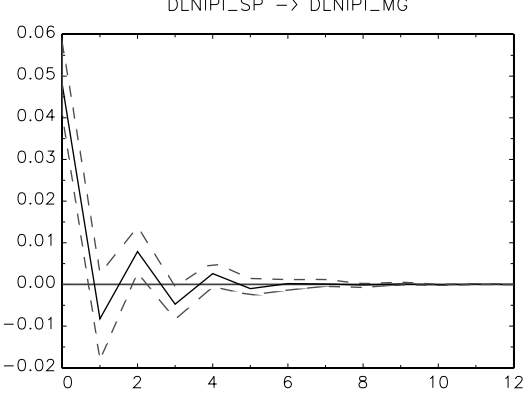

accumulated DLNIPI_SP $\rightarrow$ DLNIPI_MG

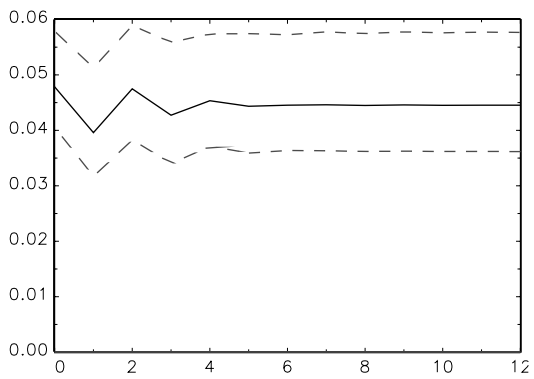

Fonte: Elaboração Própria a partir do modelo estimado.

Figura 4: Respostas da Atividade Industrial de Rio de Janeiro e Minas Gerais a choques na dinâmica Industrial de São Paulo.
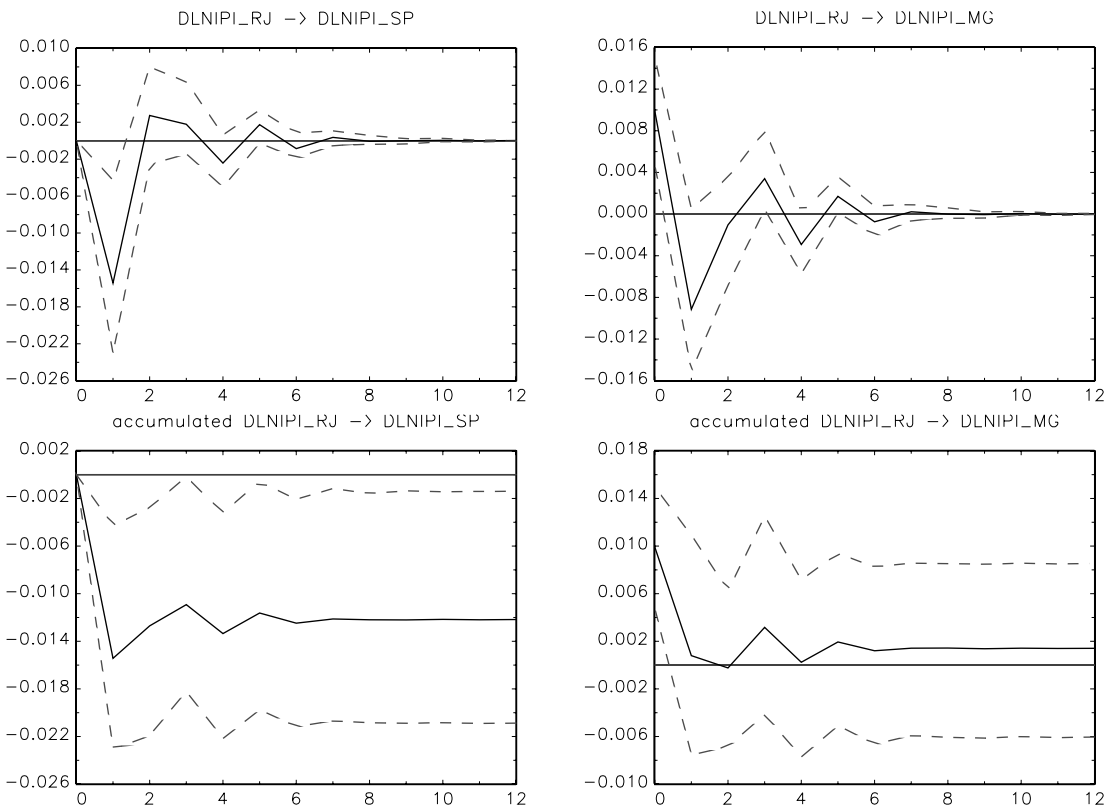

Fonte: Elaboração Própria a partir do modelo estimado.

Figura 5: Respostas da Atividade Industrial de São Paulo e Minas Gerais a choques na dinâmica Industrial do Rio de Janeiro. 
depois. A atividade Industrial do Rio de Janeiro sofre uma leve redução inicial, mas reage logo em seguida de modo que a resposta acumulada é positiva.
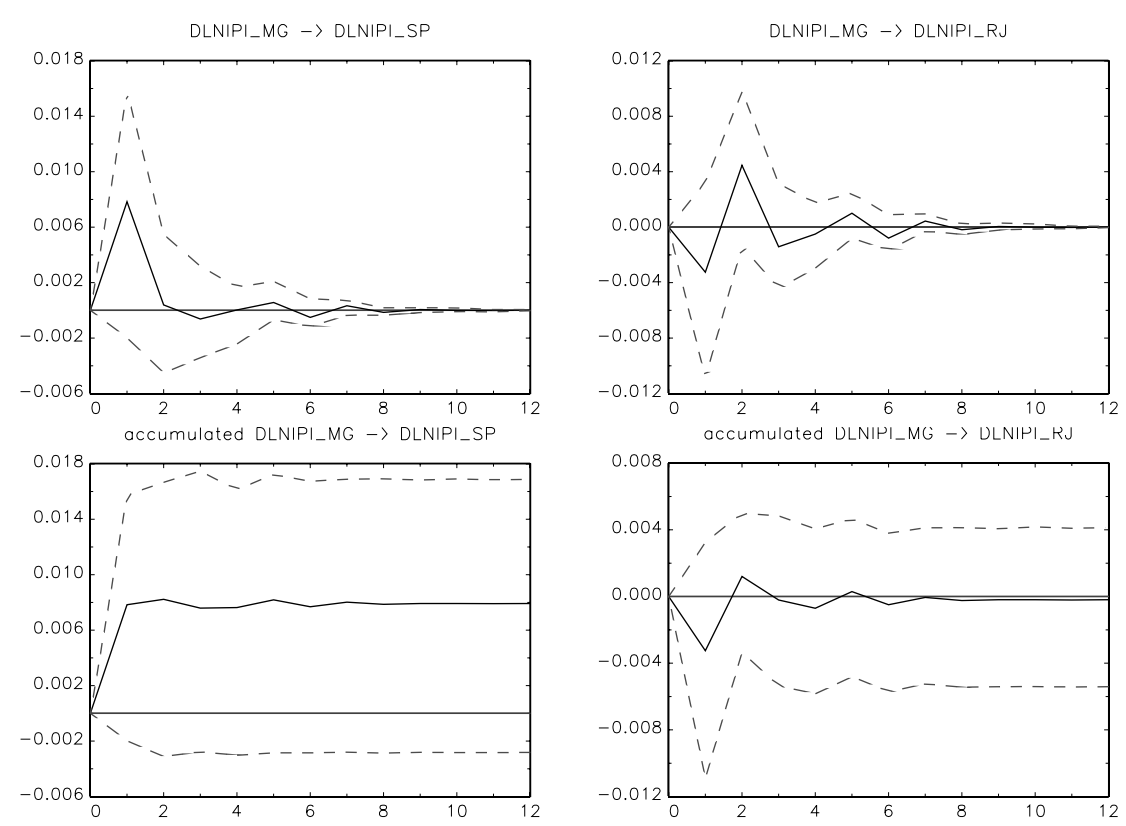

Fonte: Elaboração Própria a partir do modelo estimado.

Figura 6: Respostas da Atividade Industrial de São Paulo e Rio de Janeiro a choques na dinâmica Industrial de Minas Gerais.

Portanto, essas evidências apontam para possíveis efeitos complementares no crescimento da atividade industrial de São Paulo em Minas Gerais e no Rio de Janeiro e do estado de Minas Gerais sobre São Paulo e Rio de Janeiro, enquanto que este último parece gerar um efeito substituição, ou um maior backwash effect, rivalizando com o estado de São Paulo. Além disso, essas evidências colocam a indústria do estado de São Paulo como a grande propulsora da dinâmica intrarregional do Sudeste brasileiro, uma vez esta apresentou as maiores e mais persistentes repercussões sobre os demais estados. Esse fato também foi destacado por Perobelli et al. (2010).

A mesma análise também foi realizada para a região Sul. Os resultados indicam que um choque na dinâmica industrial do Rio Grande do Sul apresenta um efeito positivo com duração de dois meses sobre o crescimento da indústria paranaense, caindo em seguida até dissipar-se. Em condições semelhantes, o Rio Grande do Sul tem reação positiva e imediata a choques na dinâmica industrial do Paraná. Tais resultados seguem na Figura 7.

Tais resultados indicam uma forte integração na região Sul do Brasil com o estado do Paraná destacando-se em termos de interações intrarregionais. Tal resultado parece confirmar as evidências apresentadas por Perobelli et al. (2010) que identificam resultados expressivos em termos de encadeamento; ou seja, um forte processo de desconcentração da interdependência produtiva nessa região. 

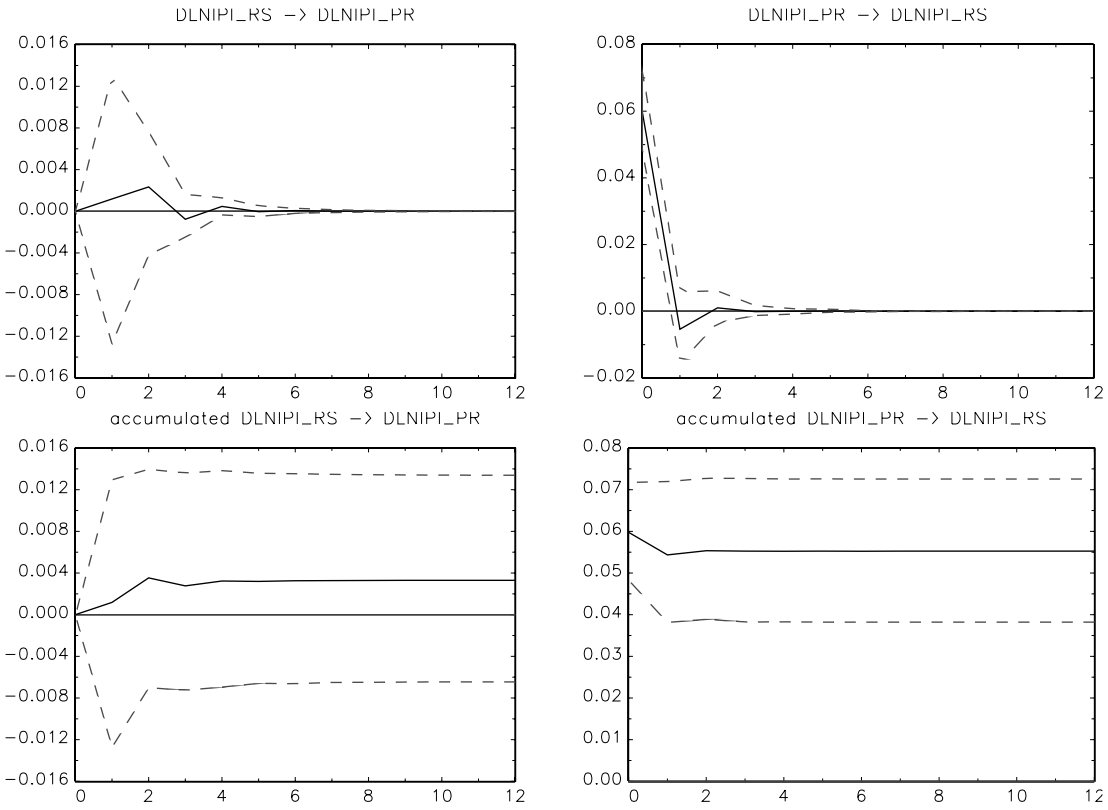

Fonte: Elaboração Própria a partir do modelo estimado.

Figura 7: Respostas da Atividade Industrial de Rio Grande do Sul e Paraná a choques na dinâmica Industrial de Paraná e Rio Grande do Sul.

\subsection{Choques no Crescimento das Exportações}

Após a identificação e análise das repercussões na atividade industrial, procedeuse uma investigação dos efeitos do comércio também em uma perspectiva intrarregional a fim de explorar melhor os resultados encontrados por Tatiwa \& Arruda (2011).

Na região Nordeste, observou-se que apenas o estado da Bahia apresentou resposta positiva na atividade industrial a choques nas exportações. Tais evidências podem justificar o resultado negativo das exportações na atividade industrial ao considerar a região Nordeste encontrado por Tatiwa \& Arruda (2011). A Figura 8 a seguir apresenta os resultados desta análise.

De fato, como mostram Haddad et al. (2002), Perobelli \& Haddad (2006a), Tatiwa \& Arruda (2011) e Magalhães (2009), considerando aspectos intrarregionais, o comércio pode estar causando efeitos assimétricos, já que os seus benefícios dependem muito de sua base exportadora e tais efeitos no Brasil mostraram-se importantes apenas para aqueles estados com melhor infraestrutura para o comércio.

Adicionalmente, pelos fatos levantados na Tabela 2, percebe-se que os estados do Ceará e Pernambuco têm sua pauta de exportações fortemente associada a bens de consumo não duráveis que representam, em sua grande maioria, alimentos, bebidas e vestuário; enquanto que na Bahia observa-se uma maior atuação dos insumos industriais e de bens de consumo duráveis. Portanto, o estado da Bahia apresenta uma pauta de exportações mais concentrada em atividades industriais de alto valor agregado e, ainda, Perobelli \& Haddad (2006a) destacam este estado na região Nordeste como aquele com melhores resultados em termos de interações comerciais.

A mesma análise para região Sudeste revela que o estado de São Paulo apre- 
DLNLXP_BA $\rightarrow D L N I P I-B A$
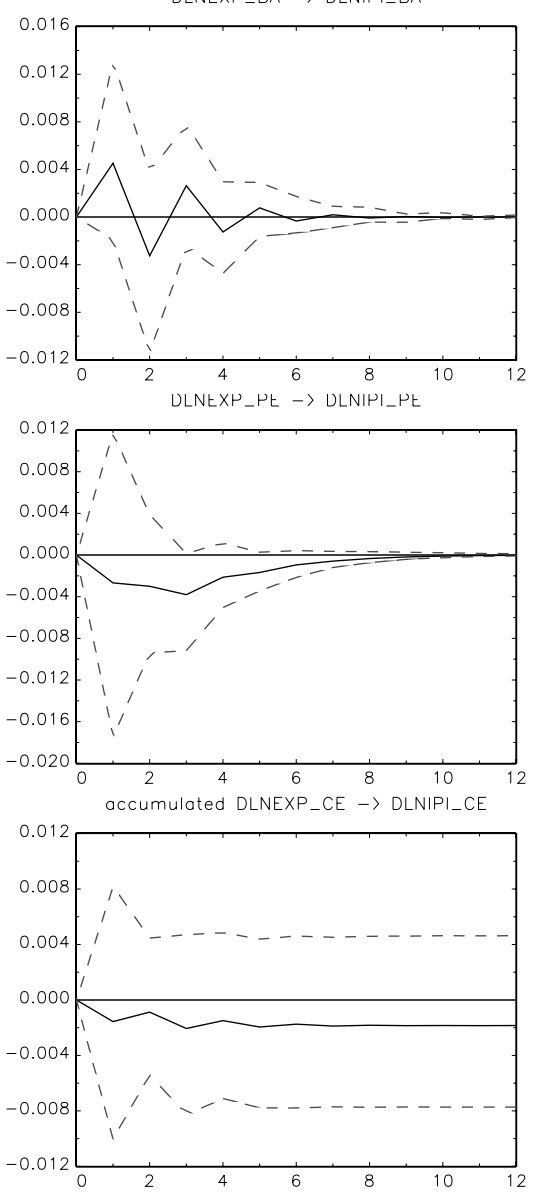

DLNEXP_CE $->$ DLNIPI_CE
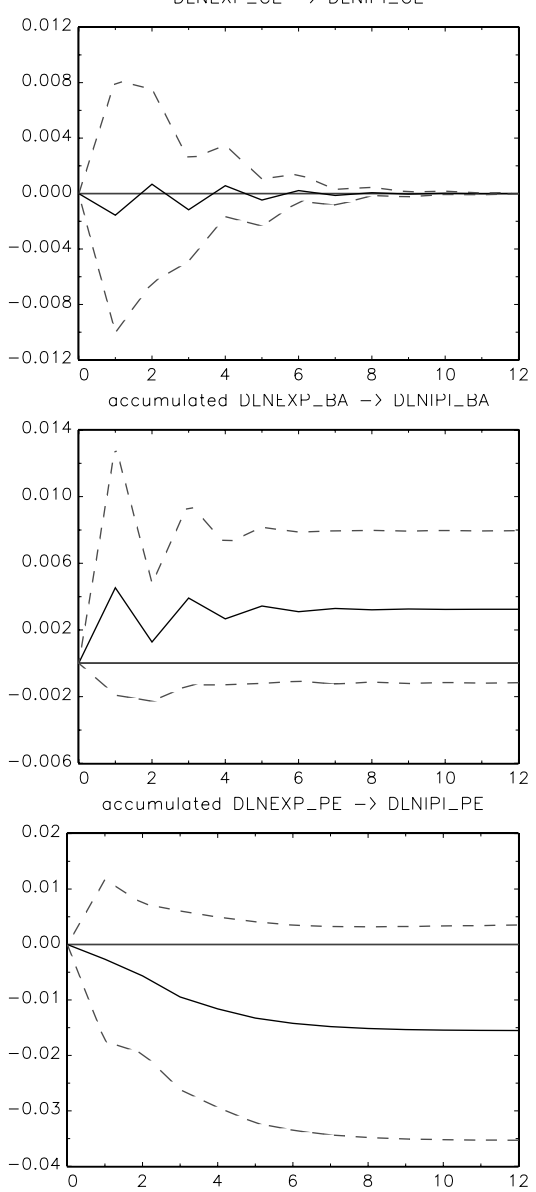

Fonte: Elaboração Própria a partir do modelo estimado.

Figura 8: Respostas da Atividade Industrial de Rio Grande do Sul e Paraná a choques na dinâmica Industrial de Paraná e Rio Grande do Sul.

sentou a maior resposta positiva do crescimento industrial em relação a um choque no crescimento das exportações, seguido do Rio de Janeiro e, ao contrário do esperado, Minas Gerais apresentou uma leve redução no primeiro mês após o choque como mostra a Figura 9. Uma possível explicação para esse comportamento inesperado nesse último estado pode ser obtida novamente por meio da análise das Tabelas 2 e 3 . Nessas tabelas verifica-se que, apesar da elevada participação de insumos industriais em sua pauta de exportações, no estado de Minas Gerais há forte atuação de produtos básicos e a menor participação em bens de capital nas exportações de sua região. Por outro lado, o estado de São Paulo teve as maiores participações de bens de capital, de equipamentos de transporte de uso industrial e de manufaturados em sua pauta de exportações. Portanto, de uma forma geral, essas evidências sugerem que a composição da pauta de exportações é importante na definição do sinal e da intensidade da resposta da dinâmica industrial em relação a choques na taxa de crescimento das exportações estaduais brasileiras.

Ao considerar os mesmos aspectos para a região Sul, observou-se que tanto a atividade industrial do estado do Rio Grande do Sul como a do Paraná rea- 
DLNEXP_SP $\rightarrow$ DLNIPI_SP
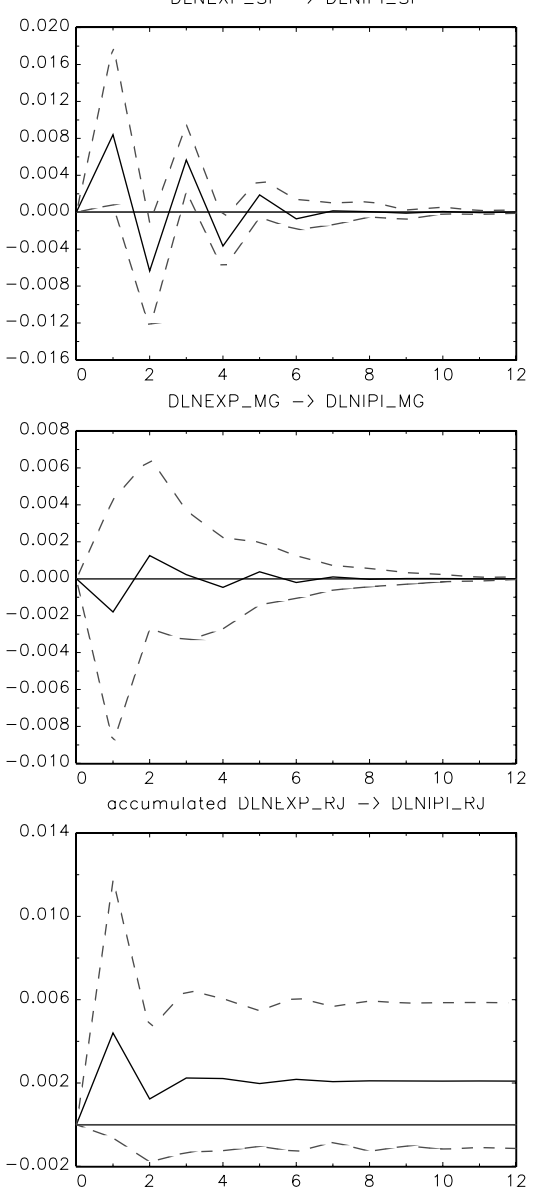

DLNEXP_RJ $\rightarrow$ DLNIPI_RJ
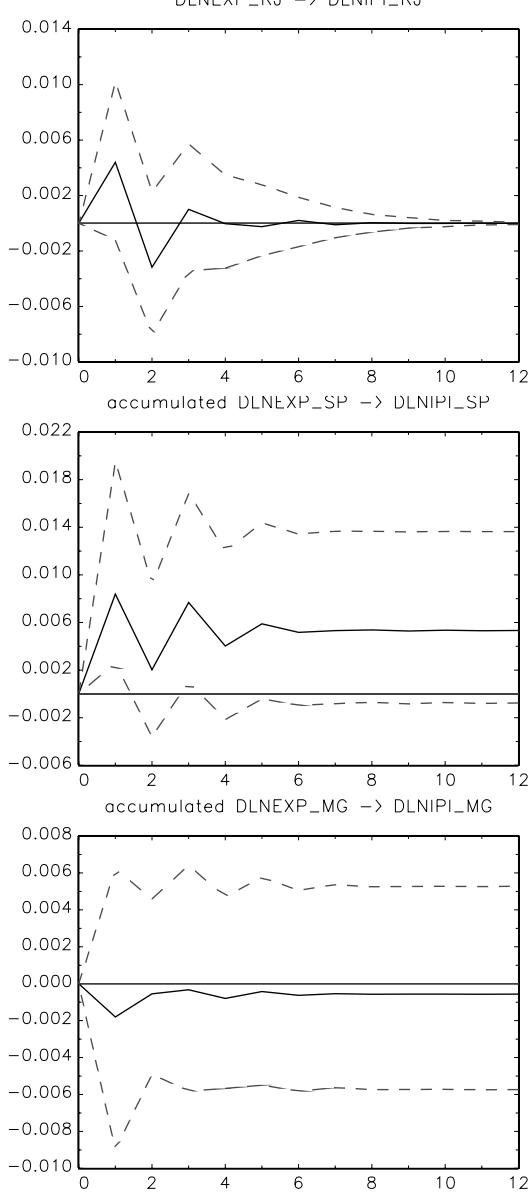

Fonte: Elaboração Própria a partir do modelo estimado.

Figura 9: Resposta da Atividade Industrial do Sudeste a Choques no Crescimento das Exportações.

giu de modo positivo a choques no crescimento de suas exportações conforme a Figura 10. Esses resultados confirmam as evidências levantadas na Tabela 2 que mostram uma importante participação de bens de capital e de insumos industriais nas pautas de exportações desses estados e, ainda, com participação majoritária de produtos manufaturados, conforme Tabela 3.

Tais resultados também convergem para os apresentados anteriormente, uma vez que destacam a infraestrutura de comércio das regiões Sudeste e Sul e, no Nordeste, do estado da Bahia, confirmando que o aumento da interação comercial brasileira tem contribuído para o agravamento das disparidades industriais intrarregionais.

\section{Considerações Finais}

O presente trabalho analisou em dinâmica intrarregional da indústria brasileira com vistas a identificar quais estados se mostraram mais relevantes na condução do crescimento industrial de suas regiões. Além disso, investigaram- 
DLNEXP_RS $\rightarrow$ DLNIPI_RS
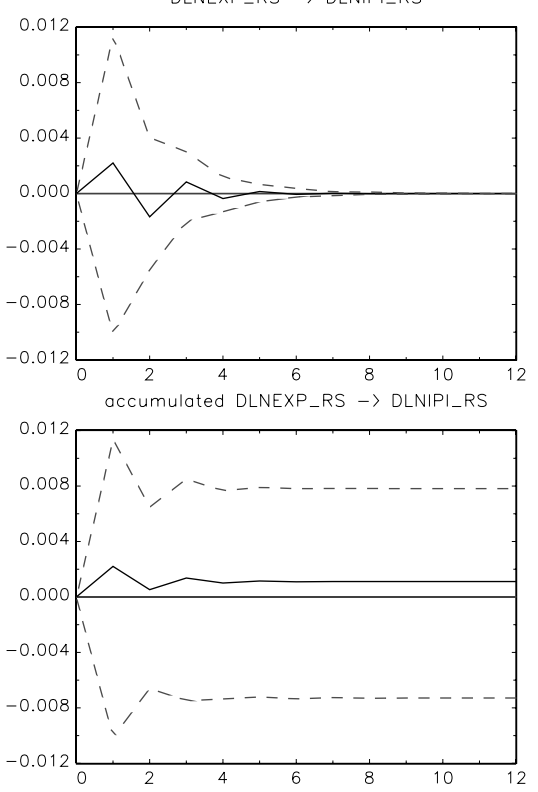

DLNEXP_PR $\rightarrow$ DLNIPI_PR
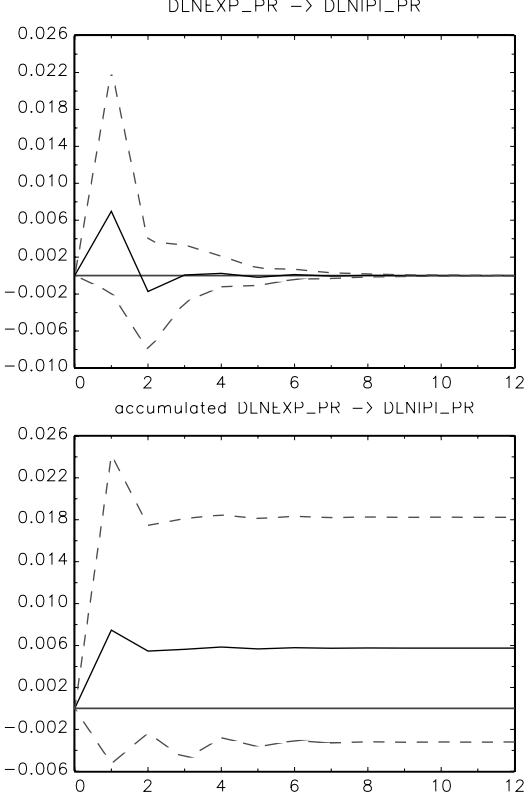

Fonte: Elaboração Própria a partir do modelo estimado.

Figura 10: Resposta da Atividade Industrial do Sul a Choques no Crescimento das Exportações.

se as repercussões de choques no crescimento das exportações sobre a atividade industrial dos estados em cada região do Brasil.

Para tal, fez-se uso de informações mensais a nível estadual, entre janeiro de 1996 e fevereiro de 2010, sobre produção industrial, inflação e exportações além da taxa de câmbio, considerada exógena nos modelos utilizados, e modelos vetoriais dinâmicos com restrições nos parâmetros autoregressivos estimados pelo método de Mínimos Quadrados Generalizados Estimável (EGLS) aplicados em sistemas de equações para cada região. As funções de impulso resposta indicaram a direção e o grau de persistência das repercussões investigadas.

Em termos de transmissão intrarregional destaca-se a atuação de São Paulo como o estado propulsor da atividade industrial na região Sudeste. No Nordeste percebe-se que tal condução é executada pela Bahia, enquanto que no Sul identificou-se a maior integração regional com o estado do Paraná tendo um leve destaque em tais repercussões. Essas evidências corroboram as apresentadas por Perobelli \& Haddad (2006a) e Perobelli et al. (2010) que apontam para os estados da Bahia e São Paulo como os mais importantes, em termos de encadeamento, de suas regiões. Os autores mostram ainda uma desconcentração industrial no Sul brasileiro que produz maiores economias de aglomeração.

Na região Nordeste, os resultados apontam ainda para possíveis efeitos complementares proporcionados pelo crescimento da atividade industrial da Bahia e do Ceará e efeitos substituição/concorrência gerados por Pernambuco. Em outras palavras, o crescimento industrial da Bahia e do Ceará parece gerar um aumento na demanda por insumos em outros estados, proporcionando um maior spread effect no crescimento industrial deles. Já o choque positivo na atividade industrial de Pernambuco parece gerar um efeito substituição, riva- 
lizando com a atividade industrial do Ceará e da Bahia, promovendo, assim, um backwash effect mais intenso. Nesse mesmo sentido, observa-se também que a atividade industrial do Rio de Janeiro parece rivalizar com a de São Paulo, no Sudeste.

Analisando os efeitos das exportações na atividade industrial, observou-se que, no Nordeste, apenas o estado da Bahia reagiu positivamente em termos de dinâmica industrial, revelando que, nessa região, é o único estado que tem se beneficiado das repercussões externas. A mesma análise para região Sudeste revelou que apenas Minas Gerais apresentou uma leve redução no primeiro mês após o choque. Por fim, ao considerar esses aspectos para a região Sul, observou-se que, tanto a atividade industrial do estado do Rio Grande do Sul como a do Paraná reagiu de modo positivo a choques em suas exportações. Tais resultados revelam o protagonismo de produtos agrícolas nas exportações do Nordeste e uma maior participação de produtos manufaturados na pauta exportadora das demais regiões.

Ou seja, considerando aspectos intrarregionais, o comércio pode estar causando efeitos assimétricos, já que os seus benefícios dependem muito de sua base exportadora e tais efeitos no Brasil mostraram-se importantes apenas para aqueles estados com melhor infraestrutura para o comércio (Haddad et al. 2002, Perobelli \& Haddad 2006a, Tatiwa \& Arruda 2011, Magalhães 2009).

De forma geral, ligando essas evidências às já existentes na literatura, podemse destacar os seguintes resultados: a) a importância de se levar em consideração os impactos do setor externo em modelos regionais; b) no Sudeste, o estado de São Paulo destaca-se como o principal gerador de repercussões positivas para o crescimento industrial dos demais estados, enquanto que, nas regiões Nordeste e Sul, esse papel é desempenhado por Bahia e Paraná, respectivamente e; c) os estados da região Sul parecem ser os mais integrados em termos de suas interdependências na atividade industrial. Por fim, políticas de qualificação de mão de obra e estímulo à $P \& D$ em setores estratégicos que permitam uma maior absorção dos efeitos positivos do comércio internacional para a atividade industrial dos estados também são relevantes para que todos os estados brasileiros possam se beneficiar de uma inserção cada vez maior no mercado internacional inibindo, assim, o agravamento de suas disparidades inter/intrarregionais.

\section{Agradecimentos}

Os autores agradecem ao Conselho Nacional de Desenvolvimento Científico e Tecnológico - CNPq pelo apoio financeiro na execução desta pesquisa e aos pareceristas anônimos pelas importantes sugestões que contribuíram para a melhoria do trabalho.

\section{Referências Bibliográficas}

Arrow, K. J. (1962), 'The economic implications of learning by doing', Review of Economic Studies 29(3), 155-173.

Azzoni, C. R. (1993), 'Equilíbrio, progresso técnico e desigualdades regionais no processo de desenvolvimento econômico', Análise Econômica 11. 
Baldwin, R., Forslid, R., Martin, F., Ottaviano, G. \& Nicoud, F. R. (2003), Economic Geography and Public Policy, Princeton University Press, Princeton.

Carlino, G. \& DeFina, R. (1995), 'The economic implications of learning by doing', Journal of Urban Economics 37, 88-106.

Christiano, L. J., Eichenbaum, M. \& Evans, C. (2005), 'Nominal rigidities and the dynamic effects of a shock to monetary policy', Journal of Political Economy 113, 1-45.

Corrado, L., Martin, R. L. \& Weeks, M. (2005), 'Identifying and interpreting regional convergence clusters across Europe', The Economic Journal 115, c133-c160.

Cromwell, B. A. (1992), 'Does california drive the west? An econometric investigation of regional spillovers', Economic Review Federal Reserve of San Francisco (2), 12-23.

Dixon, R. \& Thirlwall, A. (1975), 'A model of regional growth-rate differences on kaldorian lines', Oxford Economic Papers 21(2).

Groenewold, N., Lee, G. \& Chen, A. (2007), 'Interregional output spillovers in china: Disentangling national from regional shocks', Australasian Journal of Regional Studies 13(3).

Haddad, E. A., Domingues, E. P. \& Perobelli, F. S. (2002), 'Regional effects of economic integration: The case of Brazil', Journal of Policy Modeling 24, 453482.

Hall, P. (1992), The Bootstrap and Edgeworth Expansion, Springer, New York.

Kaldor, N. (1970), 'The case for regional policies', Scottish Journal of Political Economy.

Krugman, P. (1980), 'Scale economies, product differentiation, and the pattern of trade', American Economic Review $\mathbf{7 0 .}$

Krugman, P. (1991), Geography and Trade, MIT Press, Cambridge, MA.

Krugman, P. R. \& Venables, A. J. (1990), 'Integration and the competitiveness of peripheral industry', Centre for Economic Policy Research Discussion Paper Series 363.

Krugman, P. R. \& Venables, A. J. (1995), 'Globalization and the inequality of nations', Quarterly Journal of Economics 110, 857-880.

Kuszczak, J. \& Murray, J. D. (1986), 'A VAR analysis of economic interdependence: Canada, the United States, and the Rest of the World', Federal Reserve Bank of St. Louis Review pp. 77-131.

Kydland, F. \& Prescott, E. (1982), 'Time to build and aggregate fluctuations', Econometrica 50, 1345-1370.

Long, J. B. \& Plosser, C. (1983), 'Real business cycles', Journal of Political Economy 91, 39-69. 
Lutkepohl, H. (2005), New introduction to multiple time series analysis, Springer-Verlag Berlin Heidelberg, Germany.

Magalhães, A. S. (2009), O comércio por vias internas e seu papel sobre crescimento e desigualdade regional no Brasil, Dissertação apresentada ao curso de mestrado em economia, Centro de Desenvolvimento e Planejamento Regional da Universidade Federal de Minas Gerais.

Marshall, A. (1890), Principles of Economics, Macmillan, London.

Myrdal, G. (1963), Economic Theory and Underdeveloped Regions, Methuen, London.

Perobelli, F. S. \& Haddad, E. A. (2006a), 'Exportações internacionais e interações regionais: Uma análise de equilíbrio geral', Estudos Econômicos 36(4), 833-866.

Perobelli, F. S. \& Haddad, E. A. (2006b), 'Padrões de comércio interestadual no Brasil, 1985 e 1997', Revista Economia Contemporânea 10(1), 61-88.

Perobelli, F. S., Haddad, E. A., Mota, G. P. \& Farinazzo, R. A. (2010), 'Estrutura de interdependência inter-regional no Brasil: Uma análise espacial de insumo-produto para os anos de 1996 e 2002', Pesquisa e Planejamento Econômico 40(2), 281-325.

Porto, P. C. S. (2002), 'Mercosul and regional development in Brazil: A gravity model approach', Estudos Econômicos 32(1), 125-153.

Rickman, D. S. (2010), 'Modern macroeconomics and regional economic modeling', Journal of Regional Science 50(1), 23-41.

Romer, P. (1986), 'Increasing returns and long-run growth', Journal of Political Economy 94(5), 1002-1037.

Sims, C. (1980), 'Macroeconomics and reality', Econometrica 48, 1-48.

Smith, D. (1975), 'Neoclassical growth models and regional growth in the US', Journal of Regional Science 15(2).

Tatiwa, R. F. \& Arruda, E. F. (2011), Dinâmica da atividade industrial brasileira e seus spillovers regionais e externos, in 'XXXIX Encontro Nacional de Economia, Foz do Iguaçu'. 